\title{
Modeling Approaches to Predict Biomass Co-firing with Pulverized Coal
}

\author{
Srđan Belošević*
}

Institute of Nuclear Sciences Vinča, Laboratory for Thermal Engineering and Energy, P.O. Box 522, 11001 Belgrade, Serbia

\begin{abstract}
The main motivation for co-firing coal with biomass is carbon dioxide emission reduction, while it can also lead to sulfur oxide reduction and suppress formation of nitric oxide from fuel nitrogen. Due to the fact that the coal is mainly used for power generation in its pulverized form, the emphasis in co-firing technologies is often given to co-combustion of pulverized biomass and coal. This facilitates the modeling approach to biomass combustion, since it may be considered in a way similar to the coal dust modeling. On the other hand, when compared to the pulverized coal, there are also significant differences. The differences correspond to the biomass composition depending on its origin, to mostly larger particle size, as well as to an irregular shape of biomass particles. The paper presents a review of modeling approaches and discusses recent progress in prediction of processes during biomass co-firing with pulverized coal. The main aim of the review is to facilitate the selection of submodels and methods to those dealing with the problems of modeling and simulation of practical biomass-coal co-firing systems. Future needs, goals and challenges in the field are presented as well.
\end{abstract}

Keywords: Modeling, biomass, co-firing, pulverized coal.

\section{INTRODUCTION}

The pioneering straw and coal co-firing campaign had been undertaken in the 1990s in Denmark [1-3]. Biomass fuels represent essentially carbon dioxide $\left(\mathrm{CO}_{2}\right)$-neutral energy source, closing the carbon cycle by converting the solar energy stored via photosynthesis into thermal and electrical energy [4]. Co-firing (co-combustion) of biomass with coal in utility boilers has proved itself as a practical, low-cost and near-term option for utilizing biomass with reduction of greenhouse gas (GHG) emissions. Co-combustion of biomass with coal utilizes biomass at higher efficiency in coalfired plants compared to direct biomass-fired plants [5]. Addition of biomass to a coal-fired boiler does not impact or at worst slightly decreases the overall generation efficiency of a coal-fired power plant. Compared with other renewable options, biomass co-firing represents the most cost-effective means of renewable power generation in many cases $[6,7]$. The technology of biomass co-firing in large pulverized coal-fired boilers seems to be the most cost-effective way of biomass utilization due to the higher boiler efficiency in comparison with $100 \%$ firing biomass in smaller boilers [8].

Despite the advantages, co-firing biomass with pulverized coal imposes some serious problems (connected with specific characteristics of biomass fuels) that have to be solved in order to implement efficiently and further improve this promising technology. So, more research is needed on co-firing biomass and coal. CFD may offer an effective and

*Address correspondence to this author at the Institute of Nuclear Sciences Vinča, Laboratory for Thermal Engineering and Energy, P.O. Box 522, 11001 Belgrade, Serbia; Tel: (+381-11) 3408-343;

Fax: (+381-11) 2453-670; E-mail: v1belose@ vinca.rs low-cost toll for analysis and optimization of the processes. Importance of calculation, modeling and analysis is clear, widely used to deepen understanding of co-firing issues and problems, especially for direct co-firing. Modeling of the biomass-pulverized coal co-firing process requires sound theoretical and numerical bases in the field of both pulverized coal, as well as biomass modeling. On the other hand, the modeling of biomass is strongly related to the pulverized coal modeling approaches. When compared to the coal dust, differences correspond to the biomass composition depending on its origin, mostly larger particle size classes, as well as an irregular shape of the biomass particles. The paper presents a review of modeling approaches and discusses recent progress in prediction of processes during biomass co-firing with pulverized coal. The main aim of the review is to facilitate the selection of submodels and methods to those dealing with the problems of modeling and simulation of practical biomass-coal co-firing systems. Previous reports have focused on many of the issues related to the biomass cofiring with pulverized coal, the conclusions of which are summarized as well.

\section{BIOMASS-COAL CO-FIRING: MOTIVATION, BENEFITS, PROBLEMS AND TECHNOLOGY}

GHG emissions $\left(\mathrm{CO}_{2}\right.$, methane- $\mathrm{CH}_{4}$, etc. $)$ have become a global concern. The biomass and coal co-combustion may be the lowest-cost option for reducing greenhouse gas emissions [9]. Co-firing offers the possibility to produce energy from coal that is "light green" [10]. Combustion of biomass as a global carbon sink is highlighted in [11], discussing the important role of black carbon produced from biomass burning in the global carbon cycle. Emissions of carbon dioxide from biomass in relation to heat release are in the same range 
as for lignite [4]. The forest products industry and farming generate residues whose use as fuel is among the most environmentally beneficial biomass resources. Redirecting the residues into a fuel in some cases decreases net GHG emissions even without counting the effect of their use to supplement the fossil-derived fuels. However, the largest GHG reduction contribution comes from the supplement of fossil fuels. The GHG reduction potential of biomass is directly associated with its sustainable production. Energy crops (crops harvested solely for their energy content) represent economically and technically more challenging fuels than most residues, but they are also effective in reducing $\mathrm{CO}_{2}$ when grown in sustainable way. Residues produced in sustainable way, exhibit environmental (GHG) and economic benefits as fuels that generally exceed those of dedicated energy crops [6]. Co-firing of biomass residues, rather than crops grown for energy, brings additional GHG mitigation by avoiding $\mathrm{CH}_{4}$ release from the otherwise land filled biomass (it is believed that $\mathrm{CH}_{4}$ is 21 times more potent than $\mathrm{CO}_{2}$ in terms of global warming impact). In contrast to $\mathrm{CO}_{2}$, carbon monoxide (CO) emissions may be much higher when burning biomass, because the biomass moisture reduces the combustion efficiency [12]. Sulfur dioxide $\left(\mathrm{SO}_{2}\right)$ generally decreases in proportion to the sulfur in the fuel, which is low for many (but not all) biomass fuels $[6,13,14]$. The environmental effects of $\mathrm{SO}_{2}$ include acidification of soils and forests, corrosion of materials and buildings, as well as negative effects on health from sulfate aerosols (particulates that originate from gaseous $\mathrm{SO}_{2}$ emissions). From an environmental perspective, co-firing of bio-fuels in large combined heat and power (CHP) plants and conventional power plants provides only a small reduction in $\mathrm{SO}_{2}$ emission per unit biofuel, since these plants usually apply some form of desulphurization technology. In order to maximize the $\mathrm{SO}_{2}$ emission reduction, bio-fuels should be used in district heating plants [14]. Nitrogen oxides $\left(\mathrm{NO}_{\mathrm{x}}\right)$ may increase, decrease, or remain the same, depending on fuel, firing conditions and operating conditions [6]. $\mathrm{NO}_{\mathrm{x}}$ reduction can result from several factors, including reduced fuel nitrogen content, lower firing temperature, and staging of combustion due to early volatile burnout in the biomass fraction. Biomass appears to produce much higher ammonia $\left(\mathrm{NH}_{3}\right)$ content and a lower hydrogen cyanide $(\mathrm{HCN})$ content as a nitrogen-laden product gas compared to coal. Biomass fuels also commonly contain more moisture than coal, decreasing peak temperatures and leading to decrease in $\mathrm{NO}_{x}$. The effect of co-firing on nitric oxide (NO) has varied, with reductions between $0 \%$ and $20 \%$ [4] and even higher. For example, co-firing coal with sugar cane bagasse reduced $\mathrm{NO}_{\mathrm{x}}$ emissions by $25 \%$ (and $\mathrm{SO}_{\mathrm{x}}$ emissions by 50\%) [12]. Particulate emissions, which are such a problem when biomass is burned, are not a problem when co-firing because coal combustors are already equipped with effective particle collection systems [12].

Both biomass and coal can benefit from co-firing. Coal can mitigate the effects of variations in biomass feedstock quality and buffer the system when there is insufficient biomass feedstock, whereas biomass brings environmental and social benefits to coal plants. When a small amount of biomass is added to a coal flame, the reaction environment is primarily determined by the combustion of the coal rather than by the biomass kinetics. Premixing biomass and coal can enhance the combustion of the two fuels, whereas poorly mixed biomass and coal tend to burn independently at different rates [15]. Due to the varying physical and chemical properties of the biomass fuels, their additions have a significant impact on the characteristics of the flame, particularly the flame front and brightness. However, flame stability has been found to be little affected by the amount of biomass added in all cases studied, provided that the addition is less than $20 \%$ by mass [15]. Coals with a high moisture content or high fixed carbon (FC) content are too difficult to ignite without supplemental fuels [16]. Therefore, in considering the effective utilization of low-rank coals with high FC content, it is necessary to enhance the ignition and burn-out characteristics by adding the supplemental fuels. Cocombustion technologies for low rank coals with biomass are generally recognized as one of the candidate technologies to enhance these characteristics [16].

Biomass co-firing also faces some risks and limitations [4] and co-firing different types of biomass creates unique combustion problems. An important limit is the fraction of biomass that can be fed through pulverizers in a pulverized coal-fired plant, which is less than $4 \%$ by mass, or about $2 \%$ by heat input for a plant using bituminous coal. Higher percentages of co-firing require a separate feed system for feeding biomass directly into the boiler through separate injection ports. The thermal input from biomass to individual boilers can be in the range of $5-15 \%$ or possibly higher, depending on boiler design and biomass-feeding method [4]. At the moment, co-firing coal with a limited amount of biomass, typically $2-20 \%$, has been implemented in large-scale plants, with substitution rates typically operating at about 5\% [8]. However, within the European Union there is a drive to substantially increase the amount of substitution to around $20 \%$. The addition of biomass to coal increases fouling and the risk of slagging. There are much higher concentrations of potassium and phosphorus in the biomass compared to coals. High concentrations of silica, potassium, and chlorine occurring in some herbaceous biomass represent a special concern for deposition and corrosion in boilers [4]. The pioneering straw co-firing campaign [1-3] revealed serious problems with slagging, fouling, and corrosion encountered in conventional boilers such as stoker-fired (up to $100 \%$ straw firing) and fluidized bed boilers (with up to 50\% biomass on an energy basis). It has been established that the main reason for such operational problems lay in the high concentrations of potassium and chlorine in the annual crop biomass. Relatively limited fouling and slightly accelerated corrosion rates have been reported during co-firing of straw and coal in large pulverized utility boilers. It should be noted that the great majority of the pulverized fuel projects have operated at co-firing ratios less than $10 \%$ (on heat input basis). However, when using around $20 \%$ straw, corrosion rate increased by $100-200 \%$. As given in [4], high-temperature corrosion of boiler tubes by sulfates was reported when co-firing $20 \%$ straw in regions of the boiler reaching temperatures up to $580{ }^{\circ} \mathrm{C}$. No corrosion was observed at $10 \%$ straw co-firing, and no corrosion initiated by chlorine was observed at either co-firing level. The influences of co-firing biomass with bituminous coal (typical Upper Silesian coal with medium fouling tendency) on the fouling of boiler convection surfaces and the boiler efficiency have been studied in [9]. Three kinds of biomass have been taken into consideration: 
straw, wood and dried sewage sludge. The results confirm that the properties of additional fuels cause deterioration of the boiler efficiency as well as the changes in boilers operational parameters. The lower sintering temperature of the ash from most agricultural residues causes problems when it is co-fired with coal. This has been observed with straw, sewage sludge, and meat and bone meal. The higher chlorine content of agricultural biomass also causes corrosion problems. Although wood ash has generally a higher sintering temperature, when co-firing wood and coal, the alkali from the wood combines with sulfur from the coal to increase fouling and the risk of slagging [12]. Compared to deposits generated during coal combustion, deposits from biomass materials are denser and more difficult to remove [17].

The following concepts of co-firing biomass in connection with pulverized coal are applied [9]: 1. integration of cocombustion grate for biomass into the bottom of pulverized fuel boiler furnace, 2. grinding of biomass in coal or special mills and subsequent injection into the boiler, 3. combustion of suspension of fine biomass particles in water or oil using oil burners, 4. combustion of biomass in a separate precombustor and injection of the created flue gas into the boiler and 5. gasification of biomass [18] and combustion of the product gas as additional fuel. There are three basic types of technological configurations identified for biomass cofiring in power plants [14, 19]: direct co-firing, which means co-firing of at least two fuels in the same boiler, indirect cofiring, in which the solid fuel is gasified and subsequently combusts together with a gaseous fuel, and parallel co-firing, in which the fuels are burnt in separate boilers, but the steam produced is fed to the same turbines. Currently, direct cofiring is the most common option for biomass and coal cofiring, since specific operation costs are lower and mostly due to relatively low investment needed to turn existing coal power plants into co-firing plants. Direct co-firing of biomass and coal takes advantage of the high efficiencies obtainable in large coal-fired power plants and improves combustion due to the higher volatile content of the biomass [20]. For direct co-firing of biomass, two methods have been developed: (a) blending the biomass and coal in the fuel handling system, with the blended fuel then being fed; and (b) separate fuel handling and separate burners for the biomass, thereby avoiding impact on the conventional coal delivery system. With smaller amount of biomass, the coal and biomass are milled together and both enter the same burner. With larger amounts, the biomass is milled separately and enters the furnace in a dedicated burner with other burners operating on coal [21]. Depending upon the feeding method used for the coal and biomass fuels, three classes of co-firing can be defined [17], i.e. separate feed lines and separate burners for coal and biomass fuels, separate feed lines and a common burner: a) two inlets - coal in the primary air and biomass in the swirling secondary air (or vice versa), b) three inlets - two for primary air (central and annular), one for swirling secondary air and common feed lines and a common burner with premixed coal biomass blends.

\section{EXPERIMENTAL INVESTIGATIONS: A BRIEF REVIEW}

Experimental investigations worldwide significantly enhanced our knowledge on the process of co-firing of different biomass with coal. Information collected on the influence of biomass addition, performance of specific co-firing technologies and impact of biomass types seem to be of special importance. In general, experiments on both laboratory and pilot, or industrial scale facilities offer necessary data base for understanding and modeling the physical and chemical processes involved. Some characteristic investigations are outlined here.

The effect of co-firing straw and pulverized coal were investigated in [22], in a $2.5 \mathrm{MW}_{\text {th }}$ pilot scale burner (the straw was chopped and fed separately to the burner; the straw fractions in the range of $0-100 \%$ on a thermal basis were used) and a $250 \mathrm{MW}_{\mathrm{e}}$ utility boiler (the straw was preprocessed as pellets and ground with the coal in the mills; the straw fractions in the range of $0-20 \%$ ). Results from both tests revealed a reduction in $\mathrm{NO}$ and $\mathrm{SO}_{2}$ emission. In situ measurements, when co-firing straw and coal in a $150-\mathrm{MW}_{\mathrm{e}}$ utility boiler are given in [23], aimed to predict deposition propensities and high temperature corrosion during cocombustion of straw and coal in pulverized fuel-boilers. The straw is sucked through a stone trap-removing the heaviest particles-into the hammer mill where the straw is ground into pieces shorter than 30 or $50 \mathrm{~mm}$ depending on the sieve. The impacts of co-firing biomass and coal on flame structure and NO emissions are investigated in the context of a swirlstabilized, pilot-scale burner with straw and coal fired independently [24]. An experimental investigation on the impacts of co-firing biomass with coal focusing on biomass injection momentum indicates potentially large changes occur in flame structure and pollutant emission. The paper [15] presents the use of vision-based measurement techniques for the on-line monitoring and characterization of coal-biomass cofiring flames on an industrial-scale combustion test facility. A common type of pulverized coal was fired with five different types of biomass (swedish wood, straw, palm kernels, wood pellets and high-protein biomass) for different proportions ranging from $0 \%$ to $20 \%$ by weight and using different methods of injection. The results suggest that, due to the varying physical and chemical properties of the biomass fuels, the biomass additions impact on the characteristics of the flame, particularly the flame front (the flame ignition points) and brightness. However, the flame stability has been found to be little affected by the amount of biomass added provided that the addition is no more than $20 \%$. A system consisting of a monitoring model and an on-line measurement method is presented [25]. Results of testing campaigns show the appropriateness of the model to visualize deposit tendencies, and the possibility to determine the influence of ash deposit its on heat transfer using the measurement method. Co-firing tests with sawdust and coal have been carried out at the tangentially-fired pulverized-coal unit of FORTUM's Naantali3 CHP power plant (79 MW electricity, $124 \mathrm{MW}$ district heat and $70 \mathrm{MW}$ steam) [10]. This concept consists of a separate bio-fuel grinding system and bio- or bio-coalburners. With this new co-firing concept, it is possible to substitute 5-30\% (from fuel input) coal by renewable fuels. The following conclusions can be drawn from the extensive tests: the limiting factors for co-firing, while injecting the biomass to the boiler through the existing coal mills (i.e. simultaneous feeding), are the performances of the mills; drying capacity and coal fineness. The most cost effective concept for co-firing of coal with bio-fuels in large pulver- 
ized coal boilers is based on the separate grinding of the biomass with a simple crushing system and then burning it using the special bio-burners or bio-coal-burners. The critical factor is the particle size of the bio-fuel which is necessary to ensure proper combustion efficiency and a stable flame. According to the general opinion among researchers, the critical particle size is approximately $1 \mathrm{~mm}$. However, according to the experience in [10] from full-scale co-firing tests, the micronizing process will not be needed and the simple grinding system is sufficient to produce a stable flame and achieve a high combustion-efficiency, provided modern burners are used. With modern burner-technology, the biomass particle size distribution as large as $100 \%<8 \mathrm{~mm}$ and $30-40 \%<1 \mathrm{~mm}$ can be accepted. Experimental results for a large variety of fuel blends and conditions are presented [17]. Since biomass fuels have lower heating value compared to coal, blend flow rate has to be increased in order to have a heat throughput same as in coal-only case. This increased fuel flow rate may cause the flame to move away from the burner mouth, thereby creating flame stability problem. Lifted flames are also known to cause higher $\mathrm{NO}_{x}$ levels. Pulverized coal and coal/sawdust (isokinetic) samples were taken from the coal pipes [10]. From these samples, the coal's particle-size distribution was determined. The mill fineness results for the baseline coal and the coal/sawdust blends (33 vol.\%) are presented. Grinding coal and wood waste in the roller mills had negative effects on the coal fineness result: the amount of bigger particles was increased and the amount of smaller particles reduced. Both had a negative effect on the burn-out efficiency of the coal. Oxy-fuel combustion is a greenhouse gases abatement technology in which coal is burned using a mixture of oxygen and recycled flue gas, to obtain a rich stream of $\mathrm{CO}_{2}$ ready for sequestration. An entrained flow reactor was used in [26] to study experimentally the ignition and burnout of coals and blends with biomass under oxy-fuel conditions. The blending of biomass clearly improves the ignition properties of coal in air. The burnout of coals and blends with a mixture of $79 \% \mathrm{CO}_{2}-21 \% \mathrm{O}_{2}$ is lower than in air, but an improvement is achieved when the oxygen concentration is 30 or $35 \%$. The results of this work indicate that coal burnout can be improved by blending biomass in $\mathrm{CO}_{2} / \mathrm{O}_{2}$ mixtures.

\section{COMBUSTION CHARACTERISTICS OF BIOMASS FUELS AND DIFFERENCES FROM COAL}

The physical characteristics and chemical compositions of the fuel entering the combustors are critical to an optimum operation. Several different types of biomass can be co-fired with coal, including wood, residues from forestry and related industries, agricultural residues and biomass in refined form, such as pellets. Energy crops (i.e., plants specifically cultivated to produce energy and not by-products of an agricultural activity) are also potential candidates for co-firing. Among different coals, lignite and brown coal most closely resemble biomass, particularly wood [4]. Combustion properties are substantially different for various types of biomass and very different compared to coal, due to differences in chemical compositions and physical properties. Combustion characteristics of different biomass fuels, useful also for modeling purposes in co-firing applications are summarized in [27]. Physical, chemical and fuel properties of different types of biomass fuels are summarized in [28] and reviewed in [29]. A comparison of coal and biomass combustion is given in [20]. In [30], various issues, related to the properties and combustion of agricultural residues, are discussed.

Relative to coal, biomass generally has less carbon, more oxygen, more silica and potassium, less aluminum and iron, lower heating value, higher moisture content, and lower density and friability [28]. The biomass particle density is considerably lower than for coal particles, commonly differing by a factor of 4-7 [31]. Biomass generally has relatively low sulfur compared to coal. Also, the chlorine contents of certain bio-fuels, like straw, can exceed the levels of coal. Chlorine is a major factor in ash formation. Chlorine facilitates the mobility of many inorganic compounds, in particular potassium. The compositions of biomass among fuel types are variable, especially with respect to inorganic constituents important to the critical problems of fouling and slagging. Alkali and alkaline earth metals, in combination with other fuel elements such as silica and sulfur, are responsible for many undesirable reactions in combustion furnaces and power boilers. Reductions in the concentrations of alkali metals and chlorine yield remarkable improvements in ash fusion temperatures and facilitate the control of fouling. Biomass fuels are considered environmentally friendly for several reasons [28]. There is no net increase in $\mathrm{CO}_{2}$ as a result of burning a biomass fuel: biomass consumes the same amount of $\mathrm{CO}_{2}$ from the atmosphere during growth as is released during combustion. The alkaline ash from biomass also captures some of the $\mathrm{SO}_{2}$ and $\mathrm{CO}_{2}$ produced during combustion.

Biomass particles are large and physically complex, influencing heat and mass transfer. Biomass has low bulk energy density, it is generally moist and strongly hydrophilic, and is non-friable [6]. As with certain woody lignites, more energy is required for size reduction of biomass compared to bituminous coal [4]. It is generally unfeasible (and unnecessary) to reduce biomass to the same size or shape as coal [6]. In many demonstration plants, biomass firing occurs with particles that pass through a $1 / 4$ inches $(6.34 \mathrm{~mm}) \mathrm{mesh}$, which results in a size distribution dominantly less than about $3 \mathrm{~mm}$. Large and non-spherical biomass particles pose challenges for fuel conversion efficiency. Biomass particles too large or dense to be entrained sometimes enter the bottom ash stream with little or no conversion beyond drying [6]. However, these are generally the exception for welltuned fuel preparation systems. The low particle densities and the shape of biomass particles promote oxidation of biomass particles at rates much higher than the typically equant shape of coal particles [6]. Larger particles of a given mass burn faster when they are not spherical. Particle shape and size affect char burnout because biomass does not melt, and irregular shapes are maintained during combustion.

Biomass has significantly lower heating values than most coals. This is caused, in part, by the generally higher moisture content and, in part, by the high $\mathrm{O}_{2}$ content. Biomass heating values generally are slightly over half that of coal, biomass particle densities are about half, while bulk densities are about one fifth that of coal [6]. This results in an overall fuel density roughly one tenth that of coal. Consequently, co- 
firing biomass at a $10 \%$ heat input rate results in volumetric coal and biomass flow rates of comparable magnitudes.

Biomass is always higher in volatiles than even the lowest rank coals. Typically, biomass of the size and under the heating rates characteristic for pulverized coal co-firing yields $90-95 \%$ of its dry, inorganic-free mass during devolatilization, compared with $55-60 \%$ for most coals [6]. Biomass usually consists of $70-80 \%$ volatile matter (VM) whereas coal consists of $10-50 \%$ VM. The relative volatility (the ratio of $\mathrm{VM}$ to $\mathrm{FC}$ ) of the two types of fuel: the biomass typically has the $\mathrm{VM} / \mathrm{FC}$ ratio $>4.0$, while the $\mathrm{VM} / \mathrm{FC}$ ratio for coal is virtually always $<1.0$ [28]. In other words, biomass VM/FC ratio can be expressed as $60-80 \%$ VM to $10-$ $20 \%$ FC dry [4]. The high VM content of the biomass burns off quickly in a boiler, and the time required for complete combustion is short compared to that for a coal particle of similar size. As indicated in [20], high VM contents and low activation energies of rice husk and bamboo made the pyrolysis and subsequent volatile oxidation started earlier than for coal. The higher VM content of biomass led to two distinct stages of weight losses, with gas phase oxidation at the beginning and char oxidation in the second stage, whereas the latter dominated the entire process for coal. Results of thermogravimetric-differential thermal analysis (TG-DTA) indicated that a substantial fraction of the energy from the biomass combustion came from VM reaction, whereas almost all of the energy for coal came from char oxidation. The time scales of the VM gas-phase reactions are much less than that of the char oxidation reaction of the residual carbon in the solid phase. This difference in time scale is crucial in explaining combustion performance and pollutant emissions.

The combustion rate of biomass char is generally higher than of coal because of a more disordered carbon structure [32]. Biomass char burning rates are comparable to burning rates of high-VM bituminous coal chars. The biomass char is highly reactive because of the trapped free radicals and porous structure [28]. The char is very different from pure carbon compounds like graphite. This means a large surface area which has a large absorptive capacity. For top sizes of particles greater than $3 \mathrm{~mm}$ and fuel moisture contents exceeding $40 \%$, biomass char burnout may become a problem [4].

The burning of the char to form $\mathrm{CO}_{2}$ in the presence of sufficient oxygen and temperatures high enough is known as glowing combustion. Where temperatures are too low, or where there is insufficient oxygen for complete combustion smoldering occurs (characterized by smoking or emission of unoxidized pyrolysis products). The burning of the VMs is known as flaming combustion. Smouldering dominates at lower temperatures, while flaming dominates at higher temperatures [28].

Properties of different biomass fuels compared with coal are summarized in Table 1 (where "LHV" means "lower heating value" and "daf" means "dry ash-free"). Comparisons of pyrolysis, ignition and combustion of biomass and coal particles reveal the differences, summarized in Table 2.

The introduction of biomass into a coal-fired PC boiler adds a fuel whose dominant reaction sequence is volatilization and gas-phase combustion, rather than char formation and gas-solids oxidation as is the dominant combustion process for coal [28]. Biomass offers important advantages as a combustion feedstock, because of the high volatility of the fuel and the high reactivity of both the fuel and the resulting char. However, this may give rise to higher local peak temperatures and cause problems with pollution, while the high moisture and ash contents in biomass can cause ignition and combustion problems. Moreover, because of

Table 1. Properties of Different Biomass Fuels Compared with Coal [20]

\begin{tabular}{|c|c|c|c|c|c|c|c|c|}
\hline Fuel & LHV (daf) MJ/kg & Volatile matter $\%$ w/w (daf) & Ash content \% w/w (dry) & \multicolumn{5}{|c|}{ Ultimate analysis \% w/w (daf) } \\
\hline Wood & 18.7 & 83.0 & 1.8 & 50.5 & 6.1 & 43.0 & 0.3 & 0.1 \\
\hline Bark & 16.2 & 76.0 & 7.0 & 50.5 & 5.8 & 43.2 & 0.4 & 0.1 \\
\hline $\begin{array}{l}\text { Typical } \\
\text { bituminous coal }\end{array}$ & 31.8 & 34.7 & 8.3 & 82.4 & 5.1 & 10.3 & 1.4 & 0.8 \\
\hline
\end{tabular}

Table 2. Differences between Combustion Characteristics of Biomass and Coal [17, 27, 28]

\begin{tabular}{|c|c|c|c|c|c|}
\hline $\begin{array}{c}\text { Beginning of } \\
\text { pyrolysis of } \\
\text { biomass fuels }\end{array}$ & $\begin{array}{c}\text { The VM } \\
\text { content in } \\
\text { biomass }\end{array}$ & $\begin{array}{c}\text { Specific heating } \\
\text { value of volatiles } \\
\text { in kJ per kg }\end{array}$ & $\begin{array}{c}\text { Fractional heat } \\
\text { contribution by } \\
\text { volatiles in biomass }\end{array}$ & $\begin{array}{c}\text { Oxygen } \\
\text { content in } \\
\text { biomass char }\end{array}$ & $\begin{array}{c}\text { Gases released by } \\
\text { pyrolysis of } \\
\text { biomass chars }\end{array}$ \\
\hline $\begin{array}{c}\text { Earlier } \\
\text { compared to coal } \\
\text { fuels }\end{array}$ & $\begin{array}{c}\text { Higher } \\
\text { compared to } \\
\text { that of coal }\end{array}$ & $\begin{array}{c}\text { Lower for biomass } \\
\text { fuels compared } \\
\text { to those from coal }\end{array}$ & $\begin{array}{c}\text { It is of the order } \\
\text { of } 70 \%, \text { compared } \\
\text { to } 36 \% \text { for coal }\end{array}$ & $\begin{array}{c}\text { Higher } \\
\text { compared } \\
\text { to coal }\end{array}$ & $\begin{array}{c}\text { Mostly } \\
\mathrm{CO}, \mathrm{CO}_{2} \\
\text { and } \mathrm{H}_{2} \mathrm{O}\end{array}$ \\
$\begin{array}{c}\text { which may aggravate } \\
\text { the fouling problems }\end{array}$
\end{tabular}


the low heating values, biomass is accompanied by flame stability problems. It is anticipated that blending biomass with higher quality coal will reduce the flame stability problems, as well as minimize corrosion effects.

\section{CFD STUDIES IN THE FIELD: SCOPE AND PRACTICAL IMPORTANCE}

Computational fluid dynamics (CFD) codes turn computers into a virtual laboratory and perform the equivalent "numerical experiments" conveniently providing insight, foresight and return on investment. Numerical prediction may be used as a cost-effective tool in reducing the number of experimental tests by selecting the appropriate test campaign. Based on the theoretical as well as experimental investigations, CFD models for $100 \%$ biomass and biomass-coal combustion have been developed which simulate all key stages of the combustion including potassium release and $\mathrm{NO}_{\mathrm{x}}$ formation. However, CFD modeling techniques for biomass combustion still face significant challenges due to the lack of knowledge of the key combustion characteristics of biomass fuels. To ensure CFD simulations are more than just theoretical exercises, experimental validation is necessary to facilitate the model accuracy. With the progressing of the computing power and the development of chemical and physical models, the CFD applications in the biomass thermo-chemical conversion will more widely spread in the future.

Even until recent years, there have been still a very limited number of numerical simulations of pulverized biomass combustion using detailed combustion models and they have been focused on biomass co-firing [21]. Many CFD studies made in relation to coal combustion have been modified to apply to biomass combustion or co-firing. The cocombustion of biomass as a minor component presents an interesting intermediate situation with a high reactivity solid. There are a number of available CFD models and codes (like the commercial ones), and the suitability of the sub-models available for biomass combustion is a key factor in selecting an appropriate code. The recent CFD applications in biomass co-firing in boilers and furnaces are listed in [33] and the submodels used in these examples are summarized.

Fundamentals, technologies, and primary measures for emission reduction in combustion and co-combustion of biomass are considered in details in [34]. It is pointed out that for future improvements in furnace design, CFD can be applied as a standard tool to calculate flow distributions in furnaces and the reaction chemistry in the gas phase can be also implemented in CFD codes. A CFD modeling study [32] was carried out to examine the co-firing of pulverized coal and biomass with particular regard to the burnout of the larger diameter biomass particles. The effects of the wood particle size and shape on the burnout of the combined wood and coal char were investigated. The effect of varying the devolatilization and char combustion rate constants for the biomass component in the blend was also investigated. Ash and fouling deposition in pulverized co-firing biomass burners is studied in [35] by CFD ash deposition modeling. First deposition experimental data are used to compare, validate and discuss preliminary 2D-3D CFD post-processed calculations performed on a bench-scale combustion facility.
A CFD model that simulates the combustion of pure pulverized biomass in existing pulverized fuel coal fired furnaces has been developed and model results for the combustion of a typical wood in a $1 \mathrm{MW}$ industrial test facility have been presented in [21]. The studies of a kind can serve as a basis also for co-firing applications. The computational domain employed 300000 computational cells. Three typical wood particles are entering the furnace: $150 \mu \mathrm{m}, 320 \mu \mathrm{m}$ and $640 \mu \mathrm{m}$. The model is primarily based on coal combustion submodels using an Eulerian-Lagrangian frame of reference. Biomass specific constants that define the submodels have been investigated and employed in the simulation. In particular, potassium release during biomass combustion and the formation of $\mathrm{NO}_{\mathrm{x}}$ have been simulated. Detailed biomass models have been developed, applied to co-firing with pulverized coal in a $0.5 \mathrm{MW}$ combustion test facility and tested for a range of biomass fuels, showing promising results [36]. Simulation of the furnace has been performed using a commercial CFD code, FLUENT 6.3, within Eulerian-Lagrangian approach. Attention is focused on cofiring of two dissimilar fuels, including the combustion of the larger and irregular biomass particles which can result in the milling process. The mixtures of biomass and the coals present complex issues in definition of the size distribution. (On the other hand, burning biomass with coal shifts the particle size distribution of the ash particles from fine to coarse particles [16]). The size distributions can be handled adequately by the CFD model but there is an issue about the larger sizes of the wood and Miscanthus. The presence of larger irregular sized biomass particles impacts the particle reactivity and aerodynamic behavior. Characteristics of the submodels used in both [21] and [36] for individual processes are described further under the corresponding subtitles in this paper.

A CFD modeling study [32] has been undertaken to examine the co-firing of pulverized coal and biomass with particular regard to the burnout of the larger diameter biomass particles. The object of the work was to develop and test suitable chemical sub-models for co-firing and to examine the combustion behavior of the biomass components in the blend of coal and biomass using CFD modeling. Computations were based on a research combustion facility that replicates an industrial coal-fired power station. Three percent, by mass, of pinewood was blended with a bituminous UK coal, and the effects of the wood particle size and shape on the burnout of the combined wood and coal char were investigated. The biomass fuel wood was received as cylindrical pellets around $15 \mathrm{~mm}$ in length and $10 \mathrm{~mm}$ in diameter prior to passing through the coal mills and classifiers. For modeling purposes, wood diameters were selected based on the experimental samples received. Their volume was measured, and an approximate diameter was calculated in the range of $0.5-1 \mathrm{~mm}$. The CFD code used was FLUENT 6.122, allowing for the necessary user-defined sub-model routines and for the use of two source terms (one for the coal and one for the biomass).) The effect of varying the devolatilization and char combustion rate constants for the biomass component in the blend was also investigated. It was concluded that the combustion of small $(200 \mu \mathrm{m})$ wood particles was rapid but the rate of combustion of larger particles was dependent on their composition, size, and shape. 
Differences of two mixing methods of biomass and coal, their disadvantages and advantages are estimated using CFD based modeling tool (Ardemus) [10]. Ground biomass flow can be introduced to the coal flow near the burner area, so that the coal and biomass are mixed before they enter the furnace or biomass can be fed to the furnace via a special centre pipe so that biomass and coal particles are mixed in the flame. In another study, mixing of flue gases in co-firing has been studied numerically [6]. Namely, many boilers do not mix flue gases effectively in furnace sections, resulting in gas compositions near the boiler exit that reflect burnerto-burner variations in stoichiometry and other properties. The impact of such behavior during co-firing can be important if one is hoping, for example, that sulfur from coal will mix with biomass-derived flue gases to ameliorate corrosion. Biomass is commonly injected in only a few burners. If the gases do not mix thoroughly, many regions of the boiler will be exposed to much higher biomass co-firing percentages than suggested by the overall average. Advanced computational fluid mechanics models illustrate the impact of such striations on ash deposition, as presented in [6].

Evaluation of wood co-firing injection strategies using CFD simulations (pilot- and full-scale results) is given in [37]. The paper presents a comparison of measurements and simulation results for the well-defined conditions within a pilot-scale furnace co-firing coal and sawdust. The results provide confidence in an in-house software GLACIER's ability to model the combustion process and the resulting $\mathrm{NO}_{\mathrm{x}}$ formation during two sawdust injection strategies. This is followed by a detailed analysis of two sawdust injection approaches in a full-scale boiler. In the pilot-scale comparisons, two biomass injection schemes were studied: the comilled case (blended fuel with sawdust and Pratt seam coal was milled and injected into the furnace through a simple annulus) and the center-injection case (sawdust was injected separately through a center injector, while coal was injected through the annular region surrounding the center injector), provided two fundamentally different situations related to implementations. The modeling results produced temperature fields successfully compared with measurements for both injection strategies and various co-firing blends. In the full-scale simulations, the boiler was a $125 \mathrm{MW}$ front-wallfired unit with 16 single register low $\mathrm{NO}_{\mathrm{x}}$ burners in four elevations and an over-fire air system. The co-firing arrangement included center injection of sawdust and a wideangle, conical, biomass spreader. The sawdust replaced $7 \%$ of the coal on the basis of the total heating value and was fired through four of the 16 burners such that $50 \%$ of the firing rate for the four burners was provided by sawdust and $50 \%$ by coal. The standard fuel fired in this unit was an Eastern Bituminous coal with residue on sieve $\mathrm{R}_{50}=99 \%$ and $\mathrm{R}_{200}=68 \%$. The biomass was a green wood sieved to less than $1 / 4$ inch. The mechanism by which the $\mathrm{NO}_{\mathrm{x}}$ reduction occurred was significantly different from that observed at pilot-scale. A surprising effect was observed as sawdust was injected into the furnace: $\mathrm{NO}_{\mathrm{x}}$ concentrations actually increased in the regions near the individual sawdust-fired burners. However, additional factors resulted in an overall reduction in $\mathrm{NO}_{\mathrm{x}}$ : co-firing actually lead to lower formation rates from the coal-fired burners, lower flame temperatures reduced the thermal $\mathrm{NO}_{\mathrm{x}}$ formation and $\mathrm{NO}_{\mathrm{x}}$ formation during char oxidation. The CFD results indicated a number of potential mechanisms by which sawdust co-firing might result in $\mathrm{NO}_{\mathrm{x}}$ emissions reduction.

There is a growing interest to extend the use of alternative bio-fuels, such as agricultural residues and new energy crops and investigate their effects on the furnace performance. One example of such potential is Cynara Cardunculus, a low-cost energy crop which can be used for power generation and bio-diesel production. It is an herbaceous perennial plant, well adapted to dry areas and Mediterranean climate conditions. In [38] a CFD numerical study of co-firing coal and Cynara Cardunculus in a $350 \mathrm{MW}_{\mathrm{e}}$ utility boiler was done using a commercial CFD code, Fluent 6.3 and presented. The purpose of this work was to evaluate the combustion efficiency and the fluid dynamics and thermal behavior in the boiler when co-firing pulverized Cynara and coal under different conditions: biomass particle size, biomass cofiring percentage and location of the biomass burner in the boiler. Results from the study show interesting conclusions for their implementation in the power plant, suggesting recommendable limits in the maximum biomass substitution level and particle size in order to keep reasonable boiler efficiency and pointing out the outstanding influence of the biomass injection location.

A CFD analysis of the effects of co-firing biomass with coal is presented in the study [5]. The coal used is a Canadian high sulfur bituminous coal. The biomass is wheat straw, and it is blended with coal with a proportion of 10 and $20 \%$ (thermal basis). A simple two dimensional furnace with $1 \mathrm{~m}$ long and $0.5 \mathrm{~m}$ in width was selected in this study. Three cases have been tested in this study: pure coal, straw wheat blended with coal with a proportion of $10 \%$ and $20 \%$ (thermal basis). For each case, the initial and boundary conditions are kept constant, and only the fuel composition will be changed. Co-pulverized coal/biomass particles are burned inside a furnace with static mixers. Static mixers are placed inside the furnace for efficient turbulent flow mixing. Mixing is accomplished by controlled vortex structures generated by a series of protrusions or "tabs." A tab produces a pair of counter-rotating stream-wise vortices. The diameter of the particles at the injection is between 80 to $200 \mu \mathrm{m}$ and the mean particle diameter is $134 \mu \mathrm{m}$. Spherical particles are simulated in the Lagrangian frame of reference. Reaction is modeled by two-mixture fractions/PDF approach. One mixture fraction is used for the fuel (char) and the second for the volatiles. The dispersion of particles due to turbulence in the fluid phase is predicted using the stochastic tracking model. The devolatilization model used in this study is the two competing rates model. The heterogeneous surface reaction is modeled using the kinetics/diffusion limited rate model. The velocity vectors show the presence of four recirculation zones produced by the four tabs placed inside the furnace. These vortices will help to mix efficiently the coal or $\mathrm{coal} / \mathrm{biomass}$ particles and consequently to increase the combustion efficiency.

A full-scale coal and straw-fired utility boiler was modeled by Kaer et al. [39]. The authors used a commercial CFD code (CFX4.2) with an extended particle formulation model. The calculations were based on physical data from a fullscale co-firing facility. The calculations incorporated a $k-\varepsilon$ turbulence model, a two-step gas phase combustion formulation including chemical kinetics and a kinetic-diffusion 
model for the coal and straw char particles. The results showed a marked difference in the combustion behavior (temperature, species concentration, etc.) due in part to the large volumetric concentration of straw near the burner mouth. Devolatilization and burnout of the larger straw particles occurred further away from the burner mouth, which changed the combustion behavior. In addition, the trajectories of the chopped straw were quite different from those of the coal particles.

In [40], a new dual fuel burner designed for the co-firing of waste-derived solid fuels (e.g., biomass, refused-derived fuel, sewage sludge) with pulverized coal in practical combustors was evaluated through trials undertaken in a $0.5 \mathrm{MW}$ down-fired furnace. A new mathematical procedure was also constructed that accounts for multimode combustion of these fuels. It includes the influence of the heating and devolatilization rates of each fuel on the effective stoichiometry of the volatiles in the combustion domain depending on their respective particle trajectories. Results included for sawdustcoal flames, show the significant effect of co-firing ratio and fuel injection mode on flame ignition, combustion aerodynamics, and nitric oxide emissions. Predicted indices of the coal devolatilization rate along the particle trajectories emphasize the influence of the faster devolatilization and ignition of the sawdust on coal combustion in the near burner region. An optimum co-firing ratio in which the sawdust provided $30 \%$ of the total heat input was found to exhibit the maximum particle burnout and minimum nitric oxide emissions. Co-firing results obtained for a lower reactivity and higher nitrogen content fuel (pulverized sewage sludge) as compared with sawdust, show that the fuel injection mode had a marginal effect on burnout and NO emissions. The sawdust and sewage sludge co-firing results emphasize the need to consider both the reactivity and nitrogen content of the fuel prior to selecting an injection mode.

Nalco Mobotec's Rotating Opposed Fired Air (ROFA) system has been installed on a RAFAKO OP-230 boiler to facilitate the co-firing of biomass by improving combustion performance and biomass burnout in the boiler furnace [41]. The boiler is a 50-MW boiler burning Polish hard coal. Wood pellet was milled into a powder in hammer mills. A complete biomass handling system is installed, with the capability of firing $45 \%$ of the energy input as biomass. Motivation to co-fire biomass is to reduce greenhouse gas emissions. The boiler is a tangentially-fired pulverized coal boiler, burned through burner columns in each of the four corners. A complete biomass handling system is installed, with the capability of firing $45 \%$ of the energy input as biomass. There are six coal burner elevations and three biomass injector elevations. ROFA was employed as a method of achieving the high levels of combustion efficiency by introducing a highly turbulent environment in the upper furnace. ROFA enables efficient combustion of a large percentage of biomass co-firing (above $30 \%$ up to $100 \%$ ), including agrobiomass with high fuel nitrogen content). Extensive CFD modeling was used to design the ROFA system and to locate the proper elevation for the biomass burners. The air pressure at the nozzles required for mixing was also determined during the CFD modeling. The simulations were done by FLUENT and 1400000 computational cells in an unstructured, hybrid (all hexahedral) grid were used. For biomass the aspect ratio (length/width ratio) was much higher than for pulverized coal and a non-spherical shape was assumed with a shape factor less than one. During devolatilization, the swelling effect of the particles was also taken into account because of the significant fraction of volatile matter in the fuel. A single-rate kinetic model for biomass devolatilization was used, where the pre-exponential factor was much higher than for pulverized coal. It is commonly acknowledged that biomass char surface combustion is much faster than for pulverized coal due to enhanced mass transfer (physical shape) and intrinsic reaction kinetics (carbon microstructure). Diffusion and kinetic control models were used. For the kinetic surface reaction, a pre-exponential factor and the activation energy term were selected from the literature [32] and resulted in much faster kinetics than for coal. Three cases were compared: the baseline with low- $\mathrm{NO}_{\mathrm{x}}$ burners, the coal-only ROFA case and the biomass ROFA case. Because of better mixing with ROFA, the temperature distribution for the biomass ROFA case was significantly better than for the baseline case. This is essential to co-firing high levels of biomass. The predicted $\mathrm{NO}_{\mathrm{x}}$ reduction in co-firing case was due to the following reasons: the biomass nitrogen content was less than half of the coal and in the biomass cofiring case most of fuel nitrogen was released as $\mathrm{NH}_{3}$ in volatiles, which becomed a $\mathrm{NO}_{\mathrm{x}}$ reducing agent. In ROFA cases, a significant area with higher turbulent kinetic energy appeared at the ROFA injection zone in the upper furnace, due to high injection velocity of ROFA air. High turbulent mixing promoted the chemical reaction which was the reason for rapid burnout of $\mathrm{CO}$ in ROFA cases.

\section{MODELING APPROACHES SPECIFIC TO COM- BUSTION OF BIOMASS CO-FIRED WITH PULVER- IZED COAL: CURRENT STATUS AND RECENT DE- VELOPMENTS}

\subsection{Introductory Considerations}

Since the biomass combustion submodels are based primarily on the coal combustion submodels, it is necessary to have a solid background in coal combustion modeling. A very useful and comprehensive overview of modeling approaches in the field and submodels required in a comprehensive combustion model is given in [42]. These submodels embody mathematical and numerical representations of the fundamental principles that characterize the physicochemical phenomena of interest. The submodel review is limited to those required for characterizing non-premixed, gaseous and pulverized coal combustion and gasification processes.

The review paper [43] is concerned with the understanding of the combustion of pulverized coal and biomass from the viewpoint of computer modeling. Much of the information available for coal is transferable to biomass combustion, although there are still areas where there is a lack of information. Some specific considerations for biomass combustion are briefly outlined here as follows. In biomass combustion the water content is of significant importance and in some instances may dominate the combustion process so that in modeling the drying step may be treated separately. A number of parameters are required as inputs to existing CFD particle combustion models, such as devolatilization yields and rates, composition of volatiles, amount of char formed and 
char burning rates. Much of biomass is however burned as large lumps in bed combustors and the computer models have to be modified to account for the lower temperatures involved. However, some fuels, such as straw and sawdust are burned in a way analogous to pulverized coal. Modeling of their combustion processes then follows the conventional modeling procedure. Most of the biomass (approximately $80 \%$ or more) is released as volatiles and this can adequately be modeled using the available computer models for biomass devolatilization. The combustion of the char fraction is a minor part of the overall combustion process but poses greater problems because very few studies have been made of the combustion of chars from different biomass materials. The models developed for char combustion can be applied but there is a lack of information on reactivities, surface areas etc.

A comprehensive overview and summary of the current state of various CFD applications concerning the biomass thermochemical conversion (combustion and gasification) are given in [33]. This paper introduces the fundamentals involved in developing CFD solutions. The challenges faced by modelers using CFD in the biomass devolatilization are discussed in particular. As pointed out, many biomass devolatilization models have been developed and several reviews of these models have been made. One-step global mechanisms and semi-global multi-step mechanisms can be basically distinguished. The simplified approaches define devolatilization rates with single- or two-step Arrhenius reaction schemes. Another general biomass devolatilization model is developed extending the chemical percolation devolatilization (CPD) model from coal [44]. The common homogeneous reactions for the biomass devolatilization gases and the commonly simplified reactions models considering the overall heterogeneous reactions of char with the gas species are also summarized in [33]. The literature that introduce and review the corresponding biomass volatiles and char surface reactions kinetic relationships and parameters are cited in this paper. Additional processes and phenomena, like turbulence, porous media and multiphase flow, heat transfer with radiation, mass transfer and diffusion and the corresponding modeling approaches are reviewed as well.

Although considering a comprehensive model of thermal conversion of biomass in a packed-bed furnaces (the bed is consisting of single porous particles), the work [45] is also useful for biomass modeling in general, because it provides relevant references and summarizes the rate expressions for different homogeneous and heterogeneous reactions in conjunction with the kinetic data for drying, primary and secondary pyrolysis, gasification, and combustion of biomass.

The predictions of gas-particles two-phase flow in cofiring biomass with pulverized coal are commonly obtained by numerical solution of the time-averaged conservation equations for the gas phase in Eulerian reference frame while the particle phase equations are modeled in most cases using Lagrangian reference frame. The influence of discrete phase on the gaseous phase is usually introduced through the Particle-In-Cell approach. The standard $k-\varepsilon$ model is often used $[17,40]$, but some modifications are also applied, like RNG $k-\varepsilon$ model [21]. The dispersion of particles by turbulence is modeled by means of either stochastic models [42] or some kind of phenomenological (diffusion) models. Although ne- glected most often in complex combustion calculations, in biomass combustion and co-firing, due to relatively large biomass particles (usually irregular in shape), turbulence models are often modified to include the effects of particles on gas phase turbulence (turbulence modulation), as done in [17]. Considering radiative heat transfer, several solution methods for the radiative heat transfer equation, with varying degrees of approximation, have been developed and used. The major approaches (radiation models) can be summarized as follows [42]: statistical methods, zonal method, flux methods including the discrete-ordinates approximation, moment methods, spherical harmonics approximation and hybrid methods. In general, because biomass particles are large and irregular in shape, radiation scattering is not negligible. Different modeling approaches are used to predict the processes of devolatilization, homogeneous reactions of released gases and heterogeneous combustion of char.

The next sections emphasize main characteristics of modeling the biomass fuels in co-firing applications, different from pulverized coal modeling. The differences can be found mainly in biomass particles size, shape and prediction of the particles motion, devolatilization and combustion. Modeling approaches developed for specific processes in biomass co-firing are also pointed out, like the fragmentation of particles, ash behavior, potassium release, slagging and fouling and $\mathrm{NO}_{\mathrm{x}}$ emission. Particular considerations on biomass/coal blend modeling are provided as well. The rest of submodels, treating individual processes and phenomena (turbulence, convection-radiation heat transfer, etc.) in a similar way as for the pulverized coal are summarized, described and can be easily found in relevant literature, like $[33,42,43]$.

\subsection{Modeling of Biomass Particles: Size, Shape and Motion}

Modeling of discrete phase in co-firing applications is commonly done by numerical particle tracking in Lagrangian reference frame. As for pulverized coal, the grinding fineness of biomass particles entering the furnace strongly affects the combustion process. As known, the controlling mechanism for devolatilization of small (micro) particles is chemical kinetics, while in the case of large particles the controlling process is heat and mass transfer, which makes difference in approach to modeling strategy for different size of biomass particles. The biomass char combustion is also considerably affected by the size of particles. So, the characterization of the particle size distribution used in models is essential.

To examine the effect, two different size distributions with mean diameters of 0.5 and $2 \mathrm{~mm}$ are considered in [38]. The lower value corresponds to the typical size used in biomass combustion applications, since the biomass conversion is almost complete and a lower size will shoot up the milling consumption. The greater value has been chosen according to studies of Spliethoff and Hein [46] showing that for mean diameters greater than $2 \mathrm{~mm}$ the demand of milling energy remains practically invariable for a wide variety of biomass types. Two discrete phases have been modeled separately for coal and biomass describing for each one the spatial and time evolution of the trajectories of a representative number of particles (15840 in total) and neglecting turbulent diffusion 
effects. To characterize the fuels particle size sieve fractions provided by the plant, Rosin-Rammler distributions have been used, split up into ten intervals with the corresponding diameter size representing each interval.

In co-firing computational studies a special attention should be paid to the different definition of the problem for both discrete phases, with respect to the particles size and shape. Biomass particles are normally much bigger than pulverized coal. E.g., in the wall-fired burner model [47], biomass particles used have a mean length of $20 \mathrm{~mm}$ (maximum length of individual particle could be up to $150 \mathrm{~mm}$ ) and a mean diameter of about $2 \mathrm{~mm}$. The amount of energy required for the grinding of biomass $(2-3 \%$ of the heating value) is almost double compared to the energy required for coals $(0.9-1.2 \%$ of the heating value), [48]. The energy requirements increase significantly $(>20 \%$ of the heating value) to reduce the fibrous/moist biomass to a diameter of less than $1 \mathrm{~mm}$. Hence, with respect to the amount of energy required for the grinding of biomass, co-combustion of larger biomass particles $(>1 \mathrm{~mm}$ ) with coal is economically viably option. However, it may raises additional concerns over unburned carbon in terms of boiler operability and the marketing of ash. As far as the particle shape is concerned, most of the models used in computational fluid dynamics codes to predict solid fuel combustion rely on a spherical shape assumption. It is common to assume coal particles to be spherical. For most coals and the non-fibrous materials (like palm kernel extract and olive waste) considered in [36] the particles are almost spherical. However, some fibrous biomass particles (such as wood) may not be spherical and have a large aspect ratio (length/width ratio). Naturally, the shape of biomass particles strongly depend on the bio-fuel preparation system for continual and efficient feeding. Generally, biomass particles are very irregular, thin and long shaped. As a result, they are subjected to greater drag forces [38]. Cylinders and disks represent much better geometrical approximation to the shape of bio-fuels such as straws and woods chips. A sphere gives an extreme in terms of the volume-to-surface-area ratio, which impacts both motion and reaction of a particle. For a non-spherical particle, an additional lift force becomes important, and generally hydrodynamic forces introduce a torque on the particle as the centre of pressure does not coincide with the centre of mass. Therefore, rotation of a non-spherical particle needs to be considered. To allow for the effects of deviation of the shape from spherical a particle shape factor (less than one) is introduced, defined as the ratio of the surface area of an equal-volume sphere to the actual surface area of the non-spherical particle. Drag that acts on a non-spherical particle may be formulated as a function of spherical particle Reynolds number and shape factor [36]. Application of the biomass particle shape factor is also illustrated in [32, 47, 48]. The reactions of a non-spherical biomass particle are also quite different from that of an equal-volume spherical particle due to the actual particle surface area available and the average oxygen mass flux at particle surface.

Two cases are numerically studied in a $10 \mathrm{~m}$ long natural gas/biomass (straw) co-fired burner model [47]. In the first case, the particles are divided into three shape groups: particles with nodes (i.e. knees), particles with heads, and particles without either, representing about $11 \%, 4.3 \%$, and
$84.7 \%$ of all the mass, respectively. They all represent highly non-spherical particles, and therefore the trajectories will differ substantially from those of traditional spherical particles. The shape factor varies in a range of $0.26-0.82$. The measured 22 size-and-shape groups of biomass particles are considered. The biomass particles are assumed as solid or hollow cylinders in shape, depending on the particle group. To model accurately the motion of biomass particles, the forces that could be important are all considered in the particle force balance, which includes a drag for non-spherical particles, an additional lift due to particle non-sphericity, and a "virtual-mass" force due to relatively light biomass particles, as well as gravity and a pressure-gradient force. Since the drag and lift forces are both shape factor- and orientation-dependent, coupled particle rotation equations are resolved to update particle orientation. Equations of motion for biomass particles include both translation and rotation. Regarding translation, the method of Ganser [49] is used to determine the drag coefficient, based on the comparison and evaluation of all the methods for the drag coefficient calculation. For the rotation, two torques are taken into account in this case to calculate the net torque acting on the particle, one is caused by non-coincident center of mass and center of pressure, on the latter the aerodynamic forces act; and the other is due to the resistance on a relatively rotating body, which always acts to attenuate the relative rotation. In the second case, the non-spherical biomass particles are simplified as equal-volume spheres, without any modification to the motion and reaction due to their non-sphericity. In the equation of motion only the drag and gravity are taken into account. The particle tracking is affected by two factors: the rate at which the particle loses its weight (i.e., burning rate) and the different aerodynamic forces included in the two cases considered. The particle-related submodels have been developed for the accurate prediction of motion, inertial heating, devolatilization and char combustion for nonspherical biomass particles and incorporated into FLUENT via user-defined functions. The simulation results show a big difference between the two cases and indicate it is very significant to take into account the non-sphericity of biomass particles in order to model biomass combustion more accurately.

In [50], a model has been derived for tracking of nonspherical particles in a nonuniform flow field, which is validated by a preliminary experimental study. To validate the model, the motion of a cylindrical PVC particle is studied experimentally in originally undisturbed stagnant water which becomes non-uniform under the effect of the settling of big PVC particle. Here, the biomass particle aspect ratio is taken as the ratio between the half length of cylinder and the radius of cylinder. Two contributions to the torque acting on the particle are taken into account in this model: one is caused by non-coincident centre of mass and centre of pressure (on the latter hydrodynamic forces act) and the other is due to the resistance on a rotating body. The calculated results agree well with measurements in both translation and rotation aspects. The model allows taking into account shape details of non-spherical particles so that both the motion and the chemical reaction of particles can be modeled more reasonably. The model does not increase significantly the computational cost. It should be emphasized that in $[47$, 
50] the particle translation is expressed in an inertial frame, while particle rotation is written with respect to the particle frame.

\subsection{Modeling of Biomass Particles Combustion}

\subsubsection{Introductory Remarks}

The approach adopted in a number of works assumes that many aspects of the coal and biomass particles combustion processes are common. By analogy to coal combustion, the combustion of biomass particles can be considered in several steps: drying, devolatilization, combustion of volatiles and char combustion, together with the behavior of special components such as ash and volatile metals like potassium.

The combustion of biomass has been usually modeled, $a b$ initio, i.e., without free parameters to be determined in specific combustion tests, e.g. [51]. In these models, the kinetics of the basic transformation paths (e.g., from cellulose to tar, gas, or char) are determined by thermogravimetry at relatively low temperatures; the simulation of the combustion of the fuel particle is thus dependent on adequate descriptions for the internal flows through its pores, the external flow being much easier to model. The distinct behavior of one biomass with regard to another must then be ascribed to their composition in terms of lignin, cellulose, or hemicellulose and to the pore distribution, which are inputs to the model: in these works, in fact, the experimental combustion data serve only as a reference for comparison with the predictions of the respective models. Unfortunately, the present knowledge on the initial pore distribution and its evolution with combustion is still far from satisfactory. Significantly, the only terms in Di Blasi's model [51] denoted as "estimates" refer to the size of the pores (assumed to be monosized and unmodified throughout the process) and the permeability of the particle. The same problem arises in the simulation of pulverized coal combustion, in the case of the so-called intrinsic models [52].

During the past years, several authors have used CFD tools to explore potential applications of biomass combustion in industrial pulverized fuel plants (e.g. [32, 48]), in conjunction with the kinetic data, for both devolatilization and char oxidation, based on thermogravimetric analyses (TGA) of the raw fuel or the char prepared in a reactor, performed at low heating rates and relatively low final temperatures. In contrast, a complete and detailed set of devolatilization and combustion tests have been accomplished with a pulverized biomass in an entrained-flow reactor [53], which reproduces closely the conditions prevailing inside real boilers. The biomass tested is Cynara Cardunculus (thistle). To the authors' knowledge, no equivalent data have been reported in the open literature (until 2008), so the results presented in [53] are expected to be of value in this field by themselves. The experimental and numerical procedures, similar to those proposed for the combustion of pulverized coal by Ballester et al. [54] have been designed to derive the parameters required for the analysis of pulverized biomass combustion in practical systems. The data obtained are used as the reference data to derive the kinetic parameters, governing both pyrolysis and char oxidation, according to a simple model for the combustion of "thermally thin" particles, like in [54]. The model is the most widely used and com- monly admitted by CFD codes, although neglecting the temperature gradients inside the particles ("thermally thin particles") would underestimate the conversion times of the biomass particles of several millimeters used in some applications. A one step model is used to fit the devolatilization of the particles and a simple apparent kinetics model based on the outer particle surface is applied to the heterogeneous oxidation of the resulting char, assuming the particle to be spherical. Both devolatilization and heterogeneous reactions are described in Arrhenius fashion. As a result, only four kinetic parameters $A v, E v, A c, E c$ (pre-exponential factors $A$ and energies of activation $E$ ) plus one parameter representing the evolution of particle diameter during combustion $(\alpha)$, must be determined experimentally in order to describe the combustion of the particle. Experimental results of the devolatilization tests at $800-1175{ }^{\circ} \mathrm{C}$ showed the minimum error for $E v=11 \mathrm{~kJ} \mathrm{~mol}^{-1}$ and $A v=47.17 \mathrm{~s}^{-1}$. For the biomass particles studied $(\sim 500 \mu \mathrm{m}$ in diameter) roughly half of the total burnout time is devoted to the release of the volatiles, a fraction much greater than the typical values for pulverized coal combustion. The optimal kinetic parameters for char oxidation are found in $E c=63 \mathrm{~kJ} \mathrm{~mol}^{-1}$ and $A c=0.46 \mathrm{~g} \mathrm{~m}^{-2} \mathrm{~s}^{-1} \mathrm{~Pa}^{-1}$. Since little, if any, reduction in the diameter of the burning particles is observed during combustion, $\alpha$ has been set equal to zero. Particle density and specific heat $\rho_{p}$ and $c_{p}$, have been assumed to be similar to those of straw and wood and set to $450 \mathrm{~kg} \mathrm{~m}^{-3}$ and 2300 $\mathrm{J} \mathrm{kg}^{-1} \mathrm{~K}^{-1}$, respectively.

Similarity between the coal and biomass sub-models can be assumed, despite significant differences in mechanisms and kinetics [32]. However, even in 2000, there was no analogous CFD model available for predictions of biomass combustion processes [55]. Although the situation has been changed a lot in the meantime, there is still much to be done in this research field. The next sub-sections outline and describe the specific characteristics of modeling the individual processes during the biomass particles combustion.

\subsubsection{Modeling of Drying/Evaporation and Pyrolysis/ Devolatilization of Biomass Particles}

The process of drying in most coal combustion models is incorporated in the devolatilization element. However, in biomass combustion the moisture content is typically of significant importance. It has an impact on the heating-up and ignition of the fuel and its vaporization slows down the overall combustion of the particle. In some instances, it may even dominate the combustion process [43]. Consequently, the drying step is often treated as a separate process. During the investigation into biomass ignition [36], it was found that the amount of moisture within the biomass can have a large effect on the time to ignition. Moisture in the coal or biomass can be accounted for within CFD models by including evaporation of water from the fuel particle. For a $1 \mathrm{~mm}$ biomass particle heated at $2200 \mathrm{~K}$, the time to ignition increased from $0.0076 \mathrm{~s}$ for moisture content of $5 \%$, to $0.0264 \mathrm{~s}$ for a moisture content of $25 \%$. Due to the heating of water within the particle prior to ignition, it took 3.5 times longer to reach ignition temperature than for a low moisture content particle. Though, there are examples in which the biomass moisture content is not high. The moisture content of Cynara Cardunculus is very low and, in addition, the 
primary air preheated at $85{ }^{\circ} \mathrm{C}$ removes most of it, making this drying process negligible. Therefore in [38] devolatilization process is modeled using a single step Arrhenius form expression for both coal and biomass. For relatively low moisture content in wood used in [21] (7\% by mass) the drying process is completed within about $0.15 \mathrm{~s}$. With respect to the particle heating and drying, it has been assumed that the wood particle starts to give off moisture at a relatively low temperature of about $25^{\mathrm{O}} \mathrm{C}$ with a very low vaporization rate controlled by its saturation pressure. The rate of vaporization will increase with increase in the particle temperature until the particle reaches water boiling point where all the heat received would be used for vaporizing the moisture. The dimension of the particle is also important with respect to heating-up times, doubling the size appears to double the time to ignition. For all particle sizes, the higher the temperature of the environment during heating the faster the time to ignition. A decrease in temperature from 2200 to $1500 \mathrm{~K}$ causes a threefold increase in time to ignition [21].

Because most of the biomass is released as volatiles, accurate prediction of devolatilization process is of significant importance. The yields of gases and tars combined are known as the volatile matter. Numerical investigation of agricultural and forestry feedstocks [56] show that the yields of species: $\mathrm{CO}, \mathrm{CO}_{2}$ and $\mathrm{H}_{2} \mathrm{O}$ are similar to those produced by pyrolysis of low-rank coals, but with much higher tar (liquid) yields. In addition, the depolymerization of biomass is the predominant pyrolytic reaction, whereas in the case of coal, depolymerization reactions compete with cross-linking events, which enhances char formation. Although important differences between coal and biomass preclude direct application, existing coal devolatilization models have been commonly adapted for the biomass devolatilization. Many biomass pyrolysis/devolatilization models have been developed. Comprehensive reviews on the various models and kinetics are presented by Di Blasi [51] and also given in [33].

According to [33], one-step global mechanisms and semi-global multi-step mechanisms can be basically distinguished. The simplified approaches define devolatilization rates with single- or two-step Arrhenius reaction schemes. The one-step global mechanisms can be shown as: Biomass $\rightarrow$ Volatiles+ Char or Biomass $\rightarrow$ Tar (Bio oil) +Gases+ Char. The reaction kinetic rate is expressed in single-step Arrhenius fashion. For two-step Arrhenius reaction schemes, the kinetic devolatilization rate expressions are used proposed by Kobayashi et al. [57], with two competing rates that may control the devolatilization over different temperature ranges. The major limitation of one-step global schemes is that they are neither able to predict the composition of volatiles nor account for various components of the virgin biomass. One-step multi-reaction schemes have been developed to address these shortcomings and can be shown as: Biomass $\left(\mathrm{C}_{x} \mathrm{H}_{y} \mathrm{O}_{z}\right) \rightarrow$ Product $_{i=[\text { tar, char, gases }(\mathrm{H} 2, \mathrm{CH} 4, \mathrm{CO}, \mathrm{CO} 2, \mathrm{H} 2 \mathrm{O}, \text { etc. })]}$ and Biomass Component $(i) \rightarrow$ Volatile+Char. One of the more recent developments in one-step multi-reaction schemes for biomass fuels is the use of the distributed activation energy (DAE) approach. The major shortcoming of the one-step multi-reaction schemes is that they neglect secondary reactions (cracking of tar to light molecular weight volatiles). Multi-step semi-global schemes attempt to address this shortcoming of multi-reaction schemes by considering reaction routes for both primary and secondary reactions. Another general biomass devolatilization model is developed extending the Chemical Percolation Devolatilization (CPD) model from coal [44].

To simulate devolatilization, some CFD models [39, 43, 48] have used a relatively simple framework that treats a fuel particle as a lumped system for predicting devolatilization and combustion. This lumped, single-temperature model ignores intraparticle heat and mass transfer effects and assumes that the entire particle is isothermal and that the water vapor and volatiles generated leave the particle instantaneously. The approach is valid for small pulverized coal particles, but may not be a realistic model for biomass particles because of the large particle size and high volatile/moisture content. Intraparticle resistance to heat and mass transfer can significantly affect the devolatilization rate of millimetersized particles such as those typically used in co-firing applications. The paper [31] examines the effects of intraparticle heat and mass transfer, particle size and moisture content on the devolatilization of millimeter-sized biomass particles under conditions found in commercial coal fired boilers. A model accounts for intraparticle heat and mass transfer by diffusion and advection during particle heating, drying, and devolatilization. In [31], three different kinetic schemes were chosen for biomass devolatilization. The numbers in parentheses are the $A$ and $E$ values, respectively, for the three kinetic schemes $\left(3.3 \times 10^{7} \mathrm{~s}^{-1}, 100000 \mathrm{~J} \mathrm{~mol}^{-1}\right),\left(3.9 \times 10^{17} \mathrm{~s}^{-1}\right.$, $\left.234000 \mathrm{~J} \mathrm{~mol}^{-1}\right)$, and $\left(1.1 \times 10^{30} \mathrm{~s}^{-1}, 400000 \mathrm{~J} \mathrm{~mol}^{-1}\right)$. Biomass particles of radii up to $2 \mathrm{~mm}$ and moisture content up to $50 \%$ on a mass basis are considered. The model allows for heating, drying, and devolatilization to occur simultaneously within a particle. For example, the outer region of the particle can be undergoing devolatilization while the core of the particle is only beginning to heat up. The model assumes that the particle is spherically symmetric and variations in mass and temperature occur only in the radial direction and with time. Most biomass samples ultimately shrink when devolatilizing. The particle porosity is assumed to be constant. This assumption rarely corresponds to reality, but sophisticated pore models are beyond the scope of this effort. The model is solved numerically for a particle traveling through a onedimensional plug flow reactor. The conclusion is that intraparticle heat and mass transfer must be accounted for to reproduce the experimental results. As expected, intraparticle heat and mass effects are more significant for larger particles. These effects can significantly delay particle heating and devolatilization. This delay is significant considering the short residence times of commercial boilers and should be accounted for in computational models used to evaluate the effects of biomass-coal co-firing on boiler performance (fouling and slagging, pollutant emissions, etc.).

The devolatilization reaction rates of biomass have been widely studied using TGA or drop tube reactors, but there is little direct experimental information on their behavior in furnace flames where the heating-up rate is important. A first order kinetic rate model has been widely used for all biomass materials. Values of $A=6 \times 10^{13} \mathrm{~s}^{-1}$ and $E=2.5 \times 10^{8} \mathrm{~J} /(\mathrm{kg}$ mol) have been used and are based on values previously used for the pulverized fuel-wood [23]. Small variations in the pre-exponential factor had only a small effect. In the devola- 
tilization model, particles are assumed to be spherical and thermally thin and the kinetic expression rate for the biomass (and the coals) is only applicable in this case. The Biot Number $(B i)$ determines whether the particles are thermally thin. The regime can be defined as $B i<1$ and effectively that means particles of about $250 \mu \mathrm{m}$ are thermally thin. In the wall-fired burner model [47], co-firing natural gas and straw particles, for devolatilization of biomass, pre-exponential factor and activation energy in Arrhenius-type kinetics are taken to be $10^{6} \mathrm{~s}^{-1}$ and $7.4 \times 10^{7} \mathrm{~J} /(\mathrm{kg} \mathrm{mol})$, respectively. A single rate kinetic devolatilization model is used to predict a volatile yield from the switchgrass and coal in [48]. For switchgrass, pre-exponential factor and an activation energy are assumed to be $1.0 \times 10^{6} \mathrm{~s}^{-1}$ and $7.48 \times 10^{7} \mathrm{~J} /(\mathrm{kg} \mathrm{mol})$, respectively.

A coupled transport and reaction model is formulated in [58] to investigate the effects of various parameters on biomass pyrolysis. Heat, momentum and mass transport through a shrinking biomass particle exposed to thermal radiation is considered. The model takes into account formation of chars, tars and gases through mechanisms including both primary reactions of the virgin biomass degradation and secondary reactions of the primary tar. All main transport phenomena, unsteadiness of the gas/vapor-phase processes, variation of the reacting medium properties and particle shrinkage are also described. Numerical simulation of the problem of a wooden particle, subjected to an assigned external radiation, is used to analyze time and space evolution of the main variables and product distribution as the shrinkage parameters and the intensity of the heat flux are varied. Particular emphasis has been given to the effects of primary reaction data on particle conversion, because the dynamics of the char layer shrinkage are affected by primary degradation kinetics and size variations are directly dependent on the solid devolatilization rate. The effects of the orientation of the anisotropic wood grain relative to the one-dimensional heat flux are also investigated. Numerical simulations of the thermal degradation of a large biomass particle (particle halfthickness $\sim 0.025 \mathrm{~m}$ ) have been performed. Solid properties describe wood, the kinetic constants for a number of reactions of this complex model and the values of the heat of pyrolysis, are taken from numerous references and summarized in [58]. Product yields are also dependent on the intensity of the heat flux and its orientation with respect to the biomass grain. Secondary reactions occur to a large extent as the intensity of the heat flux is increased and for perpendicular grain heating. However, the selectivity of primary reactions is not much affected because the conversion of large biomass particles is always controlled by heat transfer.

For biomass devolatilization, the Functional Groupbiomass (FG-Biomass) model was used in [32], where three percent, by mass, of pinewood was blended with a bituminous UK coal. The values for devolatilization kinetics used here are ranging from $180 \times 10^{6}$ to $250 \times 10^{6} \mathrm{~J} \mathrm{~kg}^{-1} \mathrm{~mol}^{-1}$ for the activation energy and $2 \times 10^{13}$ to $6 \times 10^{15} \mathrm{~s}^{-1}$ for the preexponential factor. There is considerable diversity in the values of kinetic data for biomass pyrolysis rates in the literature, which results from the fact that different procedures are used to derive kinetics and also the measurements often incorporate heating effects and secondary reactions. Among the most appropriate and accurate values are those from Muller-Hagedorn et al. [59], used here (data from washed wood), but added a correction value for the influence of the metals. For the lowest rate considered $6 \times 10^{13} \exp (-250 / R T)$ [32], for a spherical biomass wood particle of diameter $750 \mu \mathrm{m}$, uniformly distributed, with a drag coefficient of 0.1 there was incomplete combustion and much of the material fell into the bottom ash hopper. Different values of pre-exponential factors and activation energies were examined [32]. These rates, appropriate to the lignin component in the biomass, showed little changes in the \% mass carbon in the bottom ash, suggesting that knots would have remained unburned as observed. If the rates, for the wood particles as a whole, were appropriate to cellulose/hemicellulose material, these took an approximate value of $6 \times 10^{15} \exp (-150 / R T)$, and combustion was seen to be completed. FG-DVC and the FG-Biomass codes were used in [36] to determine the devolatilisation of coal and biomass, respectively. In [21], it was been assumed that the devolatilization temperature of the wood commenced at about $200{ }^{\circ} \mathrm{C}$ and a single rate temperature dependent devolatilization model expressed in an Arrhenius form was employed. The data for the kinetic rate of the volatile release was calculated using the FG-Biomass model. The values obtained for the pre-exponential factor and the kinetic energy for wood were $A=6 \times 10^{13} \mathrm{~s}^{-1}$ and $E=250 \times 10^{6} \mathrm{~J} \mathrm{~kg}^{-1} \mathrm{~mol}^{-1}$.

The combined Functional Group model (for gas evolution) and statistical Depolymerization, Vaporization and Cross-linking (FG-DVC) model (for tar and char formation), usually used for coals, has been adapted in [56] to the pyrolysis of biomass (agricultural and forestry feedstocks). The FG-DVC modeling approach is a more empirical approach, but there is flexibility to add more details of the whole biomass pyrolysis chemistry. It is demonstrated to have capability to predict pyrolysis of different biomass, when extrapolated to high heating rates $\left(10^{3}{ }^{\mathrm{O}} \mathrm{C} \mathrm{s}^{-1}\right)$. The kinetic parameters and product yields are interpolated among selected database materials, by a linear interpolation scheme developed on the basis of the biomass ultimate analysis. The input data into the combustion model for wheat straw and a bituminous coal (Pittsburgh No. 8), considered in [55], are generated using the FG-DVC model, partially validated by experiments. The results indicate that, because of the low calorific nature of the straw volatiles, the combustion takes place at lower temperature, but with rapid ignition and rapid devolatilization.

The complex reactions of biomass pyrolysis and the evolution of different volatile species can be well represented by a Distributed Activation Energy Model (DAEM). For biomass devolatilization, two computer models based on DAEM are: bio-FG-DVC [56] and bio-FLASHCHAIN [60]. The DAEM is by far the most comprehensive model for analyzing complex reactions such as pyrolysis of coal and biomass in practical systems. It has been used to model the evolution of individual pyrolysis products from different precursors in a set of simultaneous first-order reactions. The model assumes that the distribution of reactivity caused by the reaction complexity can be represented by a set of independent and parallel reactions, each with its own frequency factor and activation energy. Usually, it is further assumed that all reactions share the same frequency factor, so the reactivity distribution is represented by a continuous distribution of activation energies. DAEM assumes that the evolution of a given product involves an infinite number of independent chemical reactions. It is assumed that the number of reac- 
tions is large enough to permit the distribution of energy to be expressed as $f_{i}(E)$, where " $i$ " denotes species $i$. Usually, $f_{i}(E)$ is taken to be a Gaussian distribution. For detailes see [61]. The incorporation of this model in a comprehensive CFD model is computationally expensive because of the requirement for multiple integrations for each computation cell at every time step. In [61], the integrals have been mathematically expressed in closed forms so that DAEM can be incorporated more efficiently in a CFD code. The model requires kinetic parameters as inputs which may be obtained from Thermogravimetry-Fourier Transform Infrared (TGFTIR) or Thermogravimetry-Mass Spectrometry (TG-MS) analysis of the sample. The results are presented for a number of pyrolysis products from cellulose, charcoal and a tobacco sample and compared with the experimental data. The agreement between the model prediction and the data is generally good; further improvement may be achieved by a small adjustment of the activation energy and/or the standard deviation.

In [59], the thermal degradation of three different wood species (hornbeam, walnut, and scots pine) is investigated by the analysis of TG-MS pyrolysis data. The knowledge of the kinetics of the devolatilization of wood is essential because the evolution of gaseous products affects all consecutive steps in combustion or gasification process. A suitable set of overall Arrhenius kinetic parameters for wood pyrolysis is important for plant design of technical applications. An overall model for the wood pyrolysis incorporating the separate decomposition kinetics of the main components (lignin, cellulose, and hemicellulose) is presented. Inorganic salts show a large effect on pyrolysis; therefore, washing wood with water is essential for the determination of meaningful formal kinetic parameters. Kinetic parameters for the hemicellulose, cellulose, and lignin degradation are presented. The lignin degradation is studied by monitoring specific ion fragments from lignin degradation products. It has been found that differences in wood species only result in different degradation rates for the lignin and in the early stages of the hemicellulose degradation, whereas the cellulose degradation and the degradation of the hemicellulose that decomposes at higher temperatures are similar.

The CPD model is extended to devolatilization of biomass major components based on the consideration of their chemical structure and its transformation under various mechanisms [62]. The same reaction scheme is applied for biomass as for coal. The chemical structure parameters in the original CPD model are defined directly taken from ${ }^{13} \mathrm{C}$ nuclear magnetic resonance (NMR) measurements. The kinetic rate variables are defined in Arrhenius form. In [62], a general model is developed for the devolatilization of biomass under different conditions, particularly under high heating rate (up to $1000 \mathrm{~K} \mathrm{~s}^{-1}$ ) and high temperature (up to $1400 \mathrm{~K}$ ). The model has been developed extending the CPD model from coal, developed by Fletcher et al. [44], to the three main biomass components, that is, cellulose, hemicellulose and lignin, on the basis of their specific chemical structure and behavior. The structural and kinetic parameters were fixed for the components, while the only fuel-specific input, the mass fraction of the components, can be calculated with a proposed correlation as a function of the conventional proximate and ultimate analyses. Comparisons to the meas- urements show that the model has been successfully applied to the devolatilization of various biomass types and can reasonably represent the yields of tar, light gases, and char, when considering side chains from tars as secondary products.

In the paper [63], a new modeling approach for devolatilization is proposed, based on neural networks. It is capable of handling a range of solid fuels. The neural-network structures are used to relate devolatilization data to parameters, which include the heating rate, temperature and physiochemical parameters like the ultimate and proximate analyses of the fuel. The data set involves more than 100 fuels of various types, including biomasses and coal blends for diverse experimental conditions and apparatuses. The model considers heating rate, fuel atomic ratios, and the temperature of the fuel particles to predict the volatiles released by the particles. The "learning" properties of the model implicitly facilitate all the physical conditions of devolatilization experiments, used during its training and validation phases. The neural-network model has been implemented into an existing 3D CFD multi-fuel combustion code, in particular for prediction of devolatilization effects in the near-burner region. These effects have proved to be of especial importance when attempting to assess the performance of untried coal blends, or when attempting to anticipate the likely effects of co-firing with biomass, such as forestry and agricultural waste, or sewage sludge. The predictions for high- and low- $\mathrm{NO}_{\mathrm{x}}$ burners demonstrate improved prediction of inflame data for reduced computational effort, one-fifth of that with the standard single-global-reaction devolatilization model. Devolatilization predictions have also been compared with a detailed devolatilization model (FLASHCHAIN) and found to be comparable.

\subsubsection{Modeling of Homogeneous Reactions of Biomass Volatiles}

The common homogeneous reactions for the biomass devolatilization gases are summarized in [33]. Biomass volatiles consist mostly of $\mathrm{CO}, \mathrm{CO}_{2}, \mathrm{H}_{2} \mathrm{O}$, with $\mathrm{CH}_{4}, \mathrm{H}_{2}$ and other inorganic products. Uncertainty remains for high temperature volatiles. For the modelling of oxidation of the hydrocarbon species, a global one-step reaction mechanism has been employed in [21], such as: Volatiles (Hydrocarbons) + $1.1 \mathrm{O}_{2}=\mathrm{CO}_{2}+0.9 \mathrm{H}_{2} \mathrm{O}$. The effect of the turbulence on the reaction has been modeled with the Eddy Dissipation turbulence-chemistry interaction model and the RNG $k-\varepsilon$ turbulence model. A two-step reaction mechanism is used in [36] for volatile combustion and the Eddy Dissipation model used to couple turbulence and chemical reactions. Combustion of the volatile products has been modeled in [38] using the mixed-is-reacted model. This assumption is adequate for reacting flows with high Damköhler numbers ( $D a>>1)$. Mass fractions of fuels, oxidant and products have been obtained by solving the mean and variance of the mixture fraction transport equations for each fuel. For this purpose, two beta probability-density-functions (PDF) have been assumed to model the mixture fractions fluctuations.

\subsubsection{Modeling of Biomass Char Combustion and Carbon Burnout}

For the biomass (Cynara Cardunculus, thistle) spherical particles $(\sim 500 \mu \mathrm{m}$ in diameter) studied in [53], a simple 
apparent kinetics model based on the outer particle surface is applied to the heterogeneous oxidation of the char, described in Arrhenius fashion. Modeling of char oxidation by expression $d C / d t=-N \pi d_{p}^{2} P_{2}, g /\left(1 / k_{d i f f}+1 / k_{s}\right)$ allows a direct comparison of the relative importance of external diffusion $\left(k_{\text {diff }}\right)$ and apparent kinetics $\left(k_{s}\right)$ (i.e. intrinsic kinetics + internal diffusion) on the rate on which the char is oxidized, where $k_{\text {diff }}$ is specific oxygen diffusion rate coefficient $\left(\mathrm{kgm}^{-2} \mathrm{~s}^{-1} \mathrm{~Pa}^{-1}\right), k_{s}$ is specific char oxidation rate coefficient $\left(\mathrm{kg} \mathrm{m}^{-2} \mathrm{~s}^{-1} \mathrm{~Pa}^{-1}\right)$, while $C$ is char content ( $\mathrm{kg}$ of char $/ \mathrm{kg}$ of particles), $N$ is number of coal particles $/ \mathrm{kg}$ of coal $\left(\mathrm{kg}^{-1}\right), d_{p}$ is particle diameter $(\mathrm{m})$ and $\mathrm{PO}_{2}, \mathrm{~g}$ is partial pressure of oxygen in free gas stream $(\mathrm{Pa})$. It has been determined a posteriori that for a $500-\mu \mathrm{m}$ thistle particle the ratio $k_{\text {diff }} / k_{s}$ is in the range $0.6-1.3$ for the tests reported (the minimum corresponding to the highest temperature, $\left.1300{ }^{\circ} \mathrm{C}\right)$. Hence, char particles are expected to burn under a mixed regime (oxidation limited by both kinetics and diffusion). In particular, for particles over one millimeter and slip velocities around 10 $\mathrm{m} / \mathrm{s}$, the calculations based on this model predict a mixed to diffusion-controlled regime and the correct calculation of the Nusselt and Sherwood numbers (approximately 5 or even higher) is critical for the estimation of the total burnout time. This result supports in part the approach of other researchers, who have assumed diffusion-limited oxidation in their CFD simulations of industrial burners for pulverized biomass combustion [48]. This assumption, however, should be applied very carefully and on a case-by-case basis, especially if finely pulverized fuels are used.

Gera et al. [48] numerically studied the overall burning enhancement factor for cylindrical switchgrass particles and found that the increase in surface area of the switchgrass particle was approximately $44 \%$, but the enhancement in the overall burning rate was only $31 \%$ when compared to the spherical particle of an equivalent volume. The diffusionlimited rate model used assumes that the diameter of the particles does not change. Since the mass of the particles is decreasing, the effective density decreases and needs to be updated from its mass, while the char particles become more porous. Because of the large size of the switchgrass char [48], the surface reaction proceeds at a rate determined by the diffusion of the gaseous oxidant to the surface of the particle $d m_{p} / d t=-q \Phi_{\text {en }} A_{\mathrm{p}}$, where the overall particle burning rate $q\left(\mathrm{~kg} \mathrm{~m}^{-2} \mathrm{~s}^{-1}\right)$ per unit external area $A_{\mathrm{p}}$ can be expressed in terms of a diffusion rate coefficient. The particle mass is $m_{p}(\mathrm{~kg})$, the surface area of the particle is $A_{p}\left(\mathrm{~m}^{2}\right)$, time is $t(\mathrm{~s})$, while $\Phi_{e n}$ is an enhancement factor that accounts for the non-spherical shape of the switchgrass. It is calculated by solving the ratio of the average oxygen mass flux at the surface of an oblate (ellipsoidal) particle to an equivalent spherical particle. Switchgrass char is assumed to have a constant density and the change in particle diameter during the char combustion process is calculated from the current mass of the particle. When co-firing natural gas and straw particles in the wall-fired burner model [47], because of the large biomass char, the diffusion-limited surface reaction rate model is also used, modified by an enhancement factor due to the non-sphericity of biomass particles (cylinders in shape) with respect to the equal-volume spherical particles.

For co-firing a coal (blend) and the biomass (Cynara Cardunculus), the char oxidation was modeled in [38] by using a single film model. The reaction rate was calculated for each fuel on the assumption that the process was limited by the diffusion of oxygen to the external surface of the char particle and by the char reactivity. The kinetic parameters for the char oxidation rate were obtained from Hurt and Mitchell's correlations that related the activation energy and pre-exponential factor with the fuel ultimate analysis [64]. For Cynara Cardunculus, the following char oxidation parameters were used: $A_{c}=0.3272 \mathrm{~kg} \mathrm{~m}^{-2} \mathrm{~s}^{-1} \mathrm{~Pa}^{-1}$ and $E_{c}=45758$ $\mathrm{kJ} \mathrm{kmol}^{-1}$.

The co-combustion of wheat straw and a bituminous coal has been investigated in [55], using a laminar flow CFD model of a drop-tube furnace. As the wheat straw char is highly microporous, with relatively high ash and oxygen contents, the char burnout is quicker than the analogous coal char burnout. The combustion rate of biomass char is slightly higher because the carbon has a less ordered structure. The biomass char combustion submodel is based on Smith's intrinsic model developed for coal chars [52], as well as in [36] for various kinds of milled biomass (Miscanthus, olive waste, wood and palm kernel extract) examined in co-firing with coal. The intrinsic model is also used for the combustion of the pulverized biomass (wood) char in [32]. On the basis of the most relevant data available the same activation energy $(E)$ has been applied as for the coal char but the preexponential factor $(A)$ has been increased by a factor of 2 , to correct for the fact that biomass char is partially oxygenated [65]. If the particles are flat, with a lower drag coefficient, combustion is complete with the smaller particles burning significantly. Unlike coal particles that soften and tend to become spherical, biomass particles does not melt, mainly keeping their original irregular shape and highly microporous structure during devolatilization and char burn-out, until fragmentation. Therefore, it has been concluded in [32] that the flat wood particles burn rapidly in all sizes up to 1 $\mathrm{mm}$ studied and the rate is determined by the size, shape, and drag coefficient of the particles. The slower burning component, lignin, does not burn out completely especially for particles larger than $0.5 \mathrm{~mm}$ in diameter and these particles preferentially fall into the ash hopper. Most of the char formed from biomass is derived from the lignin component, which is closest to low-rank coal in its chemical composition [56]. In [21] the pulverized wood char combustion is modeled also by using Smith's intrinsic model and the reaction rate is increased by a factor of 4 compared to coal particles, in order to represent the high burning rate of the biomass char particles. The biomass char is much more reactive than coal char, but as the combustion proceeds, the reactivity of the char particles decreases, resulting in a drop in particle temperature and a slow decrease in the particle mass.

In the case of biomass char, the burnout rate is more complicated (than for coal) as it is affected not only by the composition of the biomass fuel but also by the shape and size of the particles. Minimizing the unburned carbon in ash is a high priority in evaluating biomass fuels for utility boilers. Effects of large aspect ratio of biomass (switchgrass) particles on carbon burnout in a utility boiler and temperature distribution inside the particles have been numerically investigated in [48]. Two different models are formulated by assuming the particles are cylindrical and conduct heat internally and the particles are spherical without internal heat 
conduction. The latter model has significantly underpredicted the temperature of the particle and, consequently, the burnout, because for large biomass particles the conduction effects cannot be ignored. The current model can easily be extended to account for circular disks by making the length of the cylinder smaller than its radius. Making the height of the cylinder approaches to zero, simulates thin chips. Some results from co-firing biomass (10\% heat input) with pulverized coal ( $90 \%$ heat input) are compared with the pulverized coal (100\% heat input) simulations and coal experiments in a tangentially fired 150 MWe utility boiler. The heat and mass transfer to and from the particles is described in a sequence of four stages, where the first stage accounts for the initial heating of the particles to $400 \mathrm{~K}$, which is followed by devolatilization, char oxidation and the heating of ash. The heat transfer to the switchgrass particles from the surrounding gas and furnace is accounted for by considering the combination of conduction, convection and radiation. The temperature distribution for the large switchgrass particles is determined by solving the heat conduction equation inside the particles. The small switchgrass particles (less than $1 \mathrm{~mm}$ ), formulated in "spheres without internal conduction" or "cylindrical with internal heat conduction", provide complete burnout. However, the larger particles behave quite differently because the relative contributions of gravity, buoyancy and drag forces alter particle trajectories significantly. If larger switchgrass particles are modeled as spheres larger than $2 \mathrm{~mm}$, they would fall into the bottom ash hopper due to their poor burnout. In contrast, switchgrass modeled as cylindrical particles, because of their high burnout, experience enough aerodynamic drag to leave the combustor as fly ash. Thus, shredding or grinding of switchgrass into slivers (approximated as cylinders) would be much more favorable from a co-firing perspective. The simulations clearly show it is possible to co-fire much larger biomass (switchgrass) particles than coal without increasing any unburned carbon amount in the fly ash. This may be attributed to the high volatile content of switchgrass, as well as aerodynamic factors that can allow large switchgrass particles to achieve considerably longer residence times inside the boiler.

\subsubsection{Fragmentation of Biomass Particles}

The models used for devolatilization and combustion of the coal and biomass char most often assume a constant particle diameter during this process. However, it is well known that the final particle size distribution is nearly always significantly reduced and altered by the combustion process. Even in the case of the "shrinking core" concept in pulverized coal combustion modeling, although decreasing its diameter, the particle is assumed to remain its spherical shape during combustion. The mechanism of fragmentation due to thermal stress is usually suggested as there are always internal temperature gradients during particle heating-up, especially with large particles, such as biomass particles. These internal temperature gradients cause significant thermal stress, leading to the production of more tiny fragments than those generated from small parent particles. These processes may be important also in co-firing applications. The paper [66] reviews the literature of the fragmentation of pulverized coal and biomass during gasification, devolatilization and combustion and relate it to observed phenomena in the type of system under consideration. The difficulties of incorporating models of fragmentation into the CFD codes are also discussed.

\subsubsection{Prediction of Ash Behaviour and Slagging During Co-Firing Biomass with Coal}

A so called conceptual model has been developed to predict the ash release behavior and chemical composition of inorganics during co-firing of coal and biomass [67]. Biomass samples considered for the study include wood chips, wood bark and straw. Although biomass generally has lower ash content compared to coal, the composition of the ash in biomass is very different. The conceptual model has four main functions: introduction of a novel method to determine the speciation of biomass (using $\mathrm{pH}$ extraction analysis), classifications of inorganics within the coal and biomass important during ash formation, interaction of inorganics in biomass with those of coal during combustion and condensation of inorganics during the cooling in heat exchange areas. Preliminary studies of interaction between coal and biomass during ash formation have showed that $\mathrm{Al}, \mathrm{Si}$ and $\mathrm{S}$ elements in coal may have a 'buffering' effect on biomass alkali metals, thus reducing the release of alkali-gases which act as precursors to ash deposition and corrosion during co-firing. Combined with existing methods for coal characterization, this work can provide the basis for development of an efficient ash formation and deposition model for coal and biomass co-firing.

An investigation of slagging and fouling effects when co-firing coal/biomass blends by using a predictive model for large utility boilers is described in [8]. This model is based on the use of a zone computational method to determine the midsection temperature profile throughout a boiler, coupled with a thermo-chemical model to define and assess the risk of elevated slagging and fouling levels during cofiring of solid fuels. Besides empirically derived correlations to predict ash fouling tendency, more advanced thermochemical analyses have been also used to investigate ash melting behavior at high temperatures. The propensity of a given fuel to foul or slag is indicated by analyzing the proportion of the ash in the solid or molten phase, corresponding to the wide range of temperatures. It has been postulated that all of the ash with a melt fraction between 15 and $70 \%$ are sticky and thus may accumulate on the heat transfer surfaces, contributing to deposit formation. To estimate a specific fuels mixture ash behavior, thermodynamic equilibrium analysis has been conducted, based on the minimization of total Gibbs free energy of a system of chemical compounds. The chemical fractionation approach (based on laboratory investigations for coal/biomass combustion), indicates that alkali ash compounds, evaporized at elevated temperatures, can interact with the surface of non-reactive silica particles. This gives rise to low-melting temperature alkali silicates and contributes to the melt phase that occurs in the boiler. All the ash particles are assumed to be $10 \mu \mathrm{m}$ spheres. The application of this prediction tool is made for a $618 \mathrm{MW}_{\text {ther- }}$ mal wall-fired pulverized coal boiler, co-fired with a typical medium volatile bituminous coal and two substitute fuels, sewage sludge and sawdust, for different co-firing ratios. The modeling results revealed that, for increased co-firing of sewage sludge, an elevated risk of slagging and hightemperature fouling occurred, in complete contrast to the effects occurring with the utilization of sawdust. 


\subsubsection{Modeling of Potassium Release from Biomass Particles}

The presence of potassium $(\mathrm{K})$ in the biomass has become a significant issue since it is implicated in slagging, fouling and corrosion to the combustion system (it is generally known to decrease the ash melting temperature). However, the exact mechanism of potassium release during biomass combustion is still uncertain. Experiments suggest that the release of potassium in a combustion environment leads to $\mathrm{KOH}$ and $\mathrm{KCl}$ in the vapour phase. Fuels with a high chlorine content, such as straw, tend to form $\mathrm{KCl}$, while fuels with a low chlorine content, such as wood, mostly form $\mathrm{KOH}$. In contrast, silica can efficiently capture the potassium in the ash and so prevent potassium evaporation. The potassium release during devolatilization may occur over two temperature stages: at $300-500{ }^{\circ} \mathrm{C}$ a small amount of potassium is released whilst a significant amount is released at the temperatures of $700-1000{ }^{\circ} \mathrm{C}$. Stull, an uncertainty exists about how well the experimental findings obtained under low heating rates can be extrapolated to the high temperatures and high heating rates, existing in pulverized fuel combustion.

Potassium release during biomass combustion has been simulated in [21]. Since the chlorine content of the wood investigated is low, it is assumed that the release of potassium during devolatilization rapidly forms $\mathrm{KOH}$ (or $\mathrm{K}_{2} \mathrm{H}_{2} \mathrm{O}_{2}$ in the gas phase). In the calculations, only potassium evolution during devolatilization is considered, although it has been recognized that potassium is also released during the biomass char combustion. It is assumed that a portion of the potassium is released together with the devolatilization products, with the same rate as that of the overall volatile release. The potassium released into the gas flow will undergo complex transformations and in different temperature regimes will form $\mathrm{KOH}, \mathrm{K}_{2} \mathrm{H}_{2} \mathrm{O}_{2}, \mathrm{KCl}$ and $\mathrm{K}_{2} \mathrm{SO}_{4}$, expected to nucleate at about $800{ }^{\circ} \mathrm{C}$ forming aerosols in the flue gas. These will condense and deposit on the furnace wall and the superheater surfaces. The modeling of potassium release makes it possible to calculate both the potassium concentrations in the gas flow and the remaining potassium in the biomass ash thus paving the way to the development of the advanced ash deposition models for the combustion system.

\subsubsection{Prediction of $\mathrm{NO}_{x}$ Emission During Co-Firing Biomass with Coal}

Modeling $\mathrm{NO}_{\mathrm{x}}$ formation from biomass combustion is different from that of coal; the large particle sizes and significant irregularity in shapes of the biomass particles, as well as the presence of alkali metals in the biomass fuels can add to the complexity. Nitric oxide (NO) can be formed by the thermal mechanism or from fuel NO in an analogous way to coal. However, in biomass, fuel nitrogen (fuel-N) can exist both as heterocyclic compounds and as amino acid groups in proteins. Hence, NO can be formed from the former via the HCN intermediate by the De Soete fuel-N mechanism [68]. The protein nitrogen can be converted into both $\mathrm{HCN}$ and $\mathrm{NH}_{3}$ which react to $\mathrm{N}$-intermediates and ultimately into NO and other stable combustion products. Again, this can be described by the De Soete mechanism and the only difference between these routes is the choice of kinetic constants.
The formation of $\mathrm{NO}_{\mathrm{x}}$ has been simulated in [21], where three typical wood particles enter the furnace of a $1 \mathrm{MW}$ industrial test facility: $150 \mu \mathrm{m}, 320 \mu \mathrm{m}$ and $640 \mu \mathrm{m}$. The protein nitrogen content of wood has been estimated to be in the range of $70-90 \mathrm{wt} \%$ of the total nitrogen and therefore a combination of $\mathrm{HCN}$ and $\mathrm{NH}_{3}$ routes has been considered. The reduced flame temperature discourages the formation of thermal $\mathrm{NO}_{\mathrm{x}}$. The fuel-N produces both $\mathrm{NH}_{3}$ and $\mathrm{HCN}$ although the process can be influenced by the presence of the potassium and sodium in the gas stream. A CFD model has been applied to co-firing of pulverized coal and biomass (wood as well as Miscanthus) in a $0.5 \mathrm{MW}$ combustion test facility [36]. In general, woods contain about 70-90\% protein and amino acids and this is a reasonable assumption for Miscanthus too, the same assumption is made for other biomass types, hence due to the amount of proteins and amino acids in biomass, both routes are considered. Within the biomass calculation of $\mathrm{NO}$ it has been assumed that the ratio of $\mathrm{NO}$ produced via $\mathrm{HCN}$ and $\mathrm{NH}_{3}$ routes is $1: 3$.

The fundamentals of $\mathrm{NO}$ and $\mathrm{N}_{2} \mathrm{O}$ emissions characteristics for biomass (Hinoki sawdust) and mixtures of low-rank coals with biomass are precisely elucidated in the study [16]. Biomass, coal, and a biomass-coal mixture are burned, using an electrically heated drop tube furnace. A kinetic simulation of the $\mathrm{NO}$ and $\mathrm{N}_{2} \mathrm{O}$ behavior results is conducted, using only the homogeneous reaction schemes at constant temperature. Nevertheless, even basic information obtained by kinetic simulation at constant temperature with a fuel chemistry that is related to $\mathrm{NO}_{\mathrm{x}}$ could contribute to showing the fundamentals on $\mathrm{NO}_{\mathrm{x}}$ formation and destruction characteristics during the co-combustion. In this kinetic simulation, 29 species and 80 elementary reactions are considered, with kinetic parameters listed in [16]. The main differences between the coal, biomass, and co-combustion cases are the initial concentrations of $\mathrm{CO}, \mathrm{HCN}$, and $\mathrm{NH}_{3}$ species. Concentrations of $\mathrm{NO}$ and $\mathrm{N}_{2} \mathrm{O}$ during co-combustion are almost same as those during coal combustion, even if the input fuel-N for cocombustion becomes half of that for coal combustion.

\subsubsection{Considerations Specific to Combustion Modeling of Coal/Biomass Blends}

Combustion modeling for coal/biomass blends is complex because two chemically different fuels are involved, with biomass much more reactive and having higher volatile matter and moisture content than coal. Therefore, the offgases from each solid fuel need to be tracked separately to capture the interaction of coal and biomass combustion. Existing combustion models based on coal need to be modified to account for the effects of biomass on the overall combustion behavior of the coal/biomass blend in co-firing applications.

Sami et al. [69] and Dhanaplan et al. [70, 71] modeled and numerically studied coal-only and coal/manure blend combustion in a swirl burner by using the combustion code PCGC-2 [42], modified to incorporate a three-mixture fraction approach for blend combustion. The original PCGC-2 tracks two-mixture fractions (primary and coal-off gases) only. In fact, one of the mixture fractions is used to track the mixing of the primary and secondary gas streams and the second mixture fractions is used to track the mixing of the gases evolved from the solid fuel. One of the assumptions is 
that the gases evolved by the solid fuel are uniform in composition all through the history of the particle. This assumption may be reasonable for a single fuel type but when a mixture of two fuels is used this assumption becomes unrealistic (some new model will also be applied to coal combustion to track volatiles and char separately). This is because the devolatilization and char oxidation behavior for each fuel type will be different. This problem can be solved by tracking the gases evolved by the two fuel types separately. So, in the modified code, the third mixture fraction, manure-off gas, has been added, because the properties of manure and coal are very different and consolidating fuel-off gases into one mixture fraction would lead to unrealistic results. Now there are three mixture fractions [69, 70]: primary gas mixture fraction, coal-off gas mixture fraction and manure-off gas mixture fraction. The results are compared with those from the two mixture fraction model of the original code. While the overall simulation results from both models appear similar, there are significant differences between the predictions of local temperature distribution and species concentrations in the near burner region. This is due to the different chemical compositions of coal and manure. Abbas et al. [40] developed a mathematical model for coal/straw blend combustion. In order to account for the variability in the properties of the volatiles from each type of fuel, they used mixture fractions to track coal and straw-off gases separately. The coal-off gas and straw-off gas fractions were calculated. The gas phase equations were based on Eulerian reference frame while the particle phase equations were modeled using Lagrangian reference frame. The authors compared the results with their experiments on co-firing coal and sawdust and found good agreement between the experiments and the model results. They predicted an earlier devolatilization of coal particles due to early ignition of sawdust volatiles in the near burner region. Similar predictions were obtained by Dhanaplan et al. [70]. The increased devolatilization rate led to lower NO formation ( $40 \%$ reduction) when the sawdust was introduced through the middle of the annular coal jet.

Sami et al. [17] revised the modeling of co-firing based on models for pulverized or swirl burners. As pointed out, although combustion models exist for fuel blend combustion, they are limited in their scope and complexity. For better predictions, accurate experimental data determining the chemical reactions kinetics and a set of minimum assumptions must be employed. Moreover, if it is assumed that similar fractions of coal and biomass char, $\eta_{\text {ch,b }}$, are completely burnt (and since volatiles are completely burnt), and assuming $\mathrm{VM}_{\text {biomass }}=0.8 ; \mathrm{VM}_{\text {coal }}=0.4$ and $\eta_{\mathrm{ch}, \mathrm{b}}=0.67$, the following linear relationship for the overall combustion efficiency of the blend is obtained: $\eta_{\text {(blend) }} / \eta_{\text {(coal) }}=1+0.16458 Y_{\mathrm{b}}$, given as a function of $Y_{\mathrm{b}}$ (the mass fraction of the biomass in the blended fuel). Such a relationship has been confirmed by a detailed turbulent combustion modeling of blends [69]. Conclusions from [69] point out that the blend combustion resulted in improved combustion efficiencies compared to coal-only case.

The primary objective of the work [72] was to develop an appropriate model to explain the co-pyrolysis behaviour of lignite coal-biomass blends with different proportions. The pyrolysis behaviour of lignite coal of Indian origin, wastewood fines and their blends was studied using thermogravimetric analysis (TGA). For devolatilization of coal the
Distributed Activation Energy model was employed. A new parallel-series reaction model was used to predict pyrolysis behavior based on the experimentally obtained TG data for pure biomass. Considering the kinetic model for wood fines, it was observed that with a heating rate of $40{ }^{\circ} \mathrm{C} \mathrm{min}{ }^{-1}$, the mass loss started at $150{ }^{\mathrm{O}} \mathrm{C}$ and at about $400{ }^{\mathrm{O}} \mathrm{C}$ the first thermal event came to an end. Then the mass loss continued slowly with increasing temperature. To predict these two thermal effects, a modified reaction scheme was proposed: Biomass $\left(\right.$ rate $\left.k_{1}\right) \rightarrow$ Volatiles + Gases and Biomass (rate $\left.k_{2}\right) \rightarrow$ Char $\left(\right.$ rate $\left.k_{3}\right) \rightarrow$ Gases. The coal-biomass blend also showed two thermal events, though it was less pronounced for higher proportion of coal in blend. A new generalized model was proposed for pyrolysis of biomass with parallelseries reaction scheme, which predicted well the pyrolysis behavior of biomass over a wide range of temperature covering the two thermal events for biomass and one for coal. The co-pyrolysis behaviour of coal-biomass blend was predicted nicely by the proposed combined model using pure component kinetic data. The residual char obtained from coalbiomass blend was suitably represented by the weighted average TG data of pure lignite coal and biomass. Measured TG data indicated a linear relationship between final char yield and fraction of biomass in the blend.

The reactivities of lignite and hard coal chars, as well as different biomass chars in terms of several parameters were evaluated in [73], to determine the char blend combustion reactivity. Reaction kinetic parameters were obtained by modeling the combustion of biomass and coal chars as a single reaction, with the exception of lignite and olive kernel chars, the combustion of which was modeled by two partial reactions. A single reaction model was used in the case of hard coal-wood char blends, while for the lignite-biomass char blends two partial reactions were used. Reactivity was assessed using the specific reaction rate, as a function of conversion. The influence of biomass on combustion was greater for lignite than hard coal char mixtures. This was consistent with the fact that the biomass chars reacted in a temperature region close to lignite char and this could allow interactions to occur between the components. Evaluation of interactions between the components of the char blends was also done by the model. As known, devolatilization behavior of a lignite-biomass blend can be foreseen based on the behavior of the pure fuels. It was interesting to explore if the combustion performance of lignite (or hard coal)-biomass char blend could be predicted based on the performance of the pure chars. Modeling of char blends combustion was performed by using the activation energy and reaction order found for the pure fuels (hard coal or lignite char) and allowing only the pre-exponential factor to vary, reflecting the effect of char blend combustion. An increase of 1.2-3.5\% on the pre-exponential factor, depending on the biomass type, was sufficient to describe the kinetics of the blends.

The object of the paper [32] was to develop and test suitable chemical sub-models for co-firing and to examine the combustion behavior of the biomass components in the blend of coal and biomass using CFD modeling Three percent, by mass, of pinewood was blended with a bituminous UK coal and the effects of the wood particle size and shape on the burnout of the combined wood and coal char were investigated. The biomass fuel wood was received as cylindrical pellets around $15 \mathrm{~mm}$ in length and $10 \mathrm{~mm}$ in diameter prior 
to passing through the coal mills and classifiers. For modeling purposes, wood diameters were selected based on the experimental samples received. Their volume was measured and an approximate diameter was calculated in the range of $0.5-1 \mathrm{~mm}$. The use of complex drag coefficients and shape factors was done to account for these biomass particle shapes. For devolatilization, the FG-biomass model was used, the outputs from which was an input into the CFD combustion model. On the basis of the most relevant data available the same activation energy was applied as for the coal char but the pre-exponential factor was increased by a factor of two.

\section{CONCLUSIONS}

The main motivation for co-firing coal with biomass is emission reduction. The trend in co-firing biomass and coal is to increase the biomass-to-coal ratio and to utilize a wider range of biomass fuels. More research is needed on the cofiring, including work on continual and efficient co-feeding, co-firing mechanisms, hydrodynamic analysis of co-firing combustors, slagging, fouling and lower emissions. Offering an effective and low-cost toll for analysis and optimization of the processes, the CFD modeling is widely used to deepen understanding of co-firing issues and problems, especially for direct co-firing. The paper presents a review of modeling approaches used to predict the characteristics of the biomass co-firing with pulverized coal. The main aim of the review is to facilitate the selection of submodels to those dealing with the simulation of practical biomass-coal co-firing systems.

In modeling, similarity between the pulverized coal and biomass combustion can be assumed, despite significant differences in mechanisms and kinetics. Main characteristics of modeling the biomass particles in co-firing applications, different from pulverized coal, are emphasized in the paper, as well as modeling approaches developed for specific processes, like the fragmentation of particles, ash behavior, potassium release, slagging and fouling and $\mathrm{NO}_{\mathrm{x}}$ emission. Particular considerations on biomass/coal blend modeling are provided as well. Generally, when compared to the pulverized coal, biomass particles are much larger and also very irregular in shape, which depends on the biomass preparation system. In order to accurately model the motion of biomass particles, it is important to take into account the particle nonsphericity and all the significant forces in the particle force balance. For prediction of combustion, the actual particle surface area available and the average oxygen mass flux at the surface are important, both being shape-dependent. In biomass combustion the moisture content is typically of significant importance so that in modeling the drying step may be treated separately. The controlling mechanism for devolatilization of small particles is chemical kinetics, while in the case of large particles the controlling process is heat and mass transfer. Although important differences between coal and biomass preclude direct application, existing coal devolatilization models have been commonly adapted and made suitable for the biomass devolatilization. Among these submodels are the simplified approaches with single- or twostep Arrhenius reaction scheme, or much more complex submodels such as bio-FG-DVC, bio-FLASHCHAIN and CPD model extended to biomass. For the biomass char oxidation, different approaches are used depending on many factors like the particles size and shape. A simple apparent kinetics model, described in Arrhenius fashion, based on the outer particle surface can be often applied. In general, the biomass char particles can be expected to burn under a mixed regime (oxidation limited by both kinetics and diffusion), but because of the large size of biomass char particles in a number of cases, the diffusion-limited surface reaction rate model is used, modified due to the non-sphericity of particles. However, as the biomass char is highly microporous, the char combustion submodel is often based on Smith's intrinsic model developed for coal chars. Accounting for the intraparticle heat conduction for larger particles and the large length/diameter ratio of irregular particles play a key role in predicting the biomass char burnout.

Despite progress already made in the field, modeling techniques for biomass combustion and co-firing still face significant challenges. Some of the primary reasons are the diversity of the biomass fuels and the lack of knowledge of their key combustion characteristics and properties. Maximum particle size of a given biomass that can be fed and burned in a given pulverized coal boiler requires additional examinations, while the interaction between biomass and coal particles during combustion is in particular need of study. Much of the information available for coal is transferable to biomass combustion, although there are still areas where there is a lack of information. A more detailed physical model is needed to account for the different thermal behaviors associated to the various particle sizes and irregular shapes. A number of parameters are required as inputs to existing particle combustion models, such as devolatilization yields and rates, composition of volatiles, amount of char formed and char burning rates. Kinetics of the major steps in biomass combustion is not fully understood. There are uncertainties about the absolute values of biomass devolatilisation and char combustion as there are little data available at high temperatures. The information available from low temperature studies is influenced by catalysis and cannot be easily extrapolated to the higher temperature regime. Very few studies have been made of the combustion of chars from different biomass materials. There is a lack of information on the char reactivities, surface areas etc. The burnout rate of biomass char is more complicated than for coal as it is affected not only by the composition of the fuel but also by the shape and size of the particles. Biomass particles do not melt, mainly keeping their original irregular shape during devolatilization and char burn-out, until fragmentation. An advanced char combustion model for biomass is yet to be developed. In order to get a complete overview on the fate of the inorganics and the ash formation during co-firing of coal and biomass, additional work is to be done to determine the biomass particle size distribution of the condensed ash through agglomeration and coagulation processes. Integration of combustion modeling with advanced mineral matter chemistry, multicomponent, multiphase thermo-chemical equilibrium calculation and advanced fuel analyses is the goal for the development of reliable complex simulation tools for accurate predictions of slagging and fouling processes. Modeling of the release of potassium during combustion presents a substantial challenge because the detailed mechanism of the potassium release is not well known. It is recognized that potassium is released not only during devolatilization but also during the biomass char combustion and this process is still a subject of investigation. Coal combus- 
tion models should be also modified to include factors such as organic compounds and their effects on $\mathrm{NO}_{\mathrm{x}}$ emission. Combustion modeling of coal/biomass blends is particularly complex because two chemically different fuels are mixed and co-fired. The understanding of kinetics of pyrolysis of blends of biomass and coals is far from clear. Finally, there is still a need to develop a reliable prediction tool that can allow operators to assess the safe and economical operating limits on the level of co-firing biomass and coal that can be used in existing or new boiler units.

\section{ACKNOWLEDGEMENTS}

This work has been supported by the Republic of Serbia Ministry of Science and Technological Development (project TR-18007).

\section{REFERENCES}

[1] L. S. Pedersen, H. P. Nielsen, S. Kiil, L. A. Hansen, K. Dam-Johansen, F. Kildsig, J. Christensen, and P. Jespersen, "Fullscale co-firing of straw and coal", Fuel, vol. 75, pp. 1584-1590, October 1996.

[2] L. A. Hansen, H. P. Nielsen, F. J. Frandsen, K. Dam-Johansen, S. Horlyck, and S. Karlsson, "Influence of deposit formation on corrosion at a straw-fired boiler", Fuel Process. Technol., vol. 64, pp. 189-209, May 2000.

[3] K. Wieck-Hansen, P. Overgaard, and O. H. Larsen, "Co-firing coal and straw in a 150 MWe power boiler experiences", Biomass Bioenergy, vol. 19, pp. 395-409, December 2000.

[4] E. A. Sondreal, S. A. Benson, J. P. Hurley, M. D. Mann, J. H. Pavlish, M. L. Swanson, G. F. Weber, and C. J. Zygarlicke, "Review of advances in combustion technology and biomass co-firing", Fuel Process. Technol., vol. 71, pp. 7-38, June 2001.

[5] C. Ghenai and I. Janajreh, "CFD analysis of the effects of co-firing biomass with coal", 602j, in GCREEDER 2009, Amman, Jordan, March 31-April 2, 2009, pp. 1-7.

[6] L. Baxter, "Biomass-coal co-combustion: opportunity for affordable renewable energy", Fuel, vol. 84, pp. 1295-1302, July 2005.

[7] K. R. G. Hein, and J. M. Bemtgen, "EU clean coal technology-cocombustion of coal and biomass", Fuel Process. Technol., vol. 54, pp. 159-169, March 1998.

[8] P. Plaza, A. J. Griffiths, N. Syred, and T. Rees-Gralton, "Use of a predictive model for the impact of co-firing coal/biomass blends on slagging and fouling propensity", Energy Fuels, vol. 23, pp. 34373445, April 2009.

[9] M. Pronobis, "The influence of biomass co-combustion on boiler fouling and efficiency", Fuel, vol. 85, pp. 474-480, March 2006.

[10] K. Savolainen, "Co-firing of biomass in coal-fired utility boilers", Appl. Energy, vol. 74, pp. 369-381, March-April 2003.

[11] R. Ball, "Combustion of biomass as a global carbon sink", Open Thermodyn. J., vol. 2, pp. 106-108, 2008. [Open Access]. Available: www.bentham.org/open/totherj/index.htm.

[12] C. Briens, J. Piskorz, and F. Berruti, "Biomass valorization for fuel and chemicals production - a review", Int. J. Chem. Reactor Eng., vol. 6: R2, pp. 1-49, January 2008. [Online]. Available: http:// www.bepress.com/ijcre/vol6/R2 [Accessed Nov. 12, 2009].

[13] P. M. Gvero, D. Stojiljkovic, Dj, Vojinovic, G. Tica, and S. Djukic, "Combustion of coal and biomass mixtures as possibility of sulfur oxides emission reduction", in $12^{\text {th }}$ Symposium on Thermal Science and Engineering of SCG, Sokobanja, Serbia, October 1821, 2005, pp. 1-6 (in Serbian).

[14] K. Ericsson, "Co-firing-A strategy for bioenergy in Poland?", Energy, vol. 32, pp. 1838-1847, October 2007.

[15] G. Lu, Y. Yan, S. Cornwell, M. Whitehouse, and G. Riley, "Impact of co-firing coal and biomass on flame characteristics and stability", Fuel, vol. 87, pp. 1133-1140, June 2008.

[16] A. Gani, K. Morishita, K. Nishikawa, and I. Naruse, "Characteristics of co-combustion of low-rank coal with biomass", Energy Fuels, vol. 19, pp. 1652-1659, May 2005.

[17] M. Sami, K. Annamalai, and M. Wooldridge, "Co-firing of coal and biomass fuel blends", Prog. Energy Combust. Sci., vol. 27, Issue 2, pp. 171-214, 2001.
[18] K. Maniatis, "Progress in biomass gasification: an overview", in Progress in Thermochemical Biomass Conversion, vol. 1, A. V. Bridgwater, Ed. Oxford: Blackwell Science Ltd, 2001, pp. 1-31.

[19] S. van Loo and J. Koppejan, Ed., Handbook of Biomass Combustion and Co-firing. London: EarthScan, 2008.

[20] J. Dai, S. Sokhansanj, J. R. Grace, X. Bi, C. J. Lim, and S. Melin, "Overview and some issues related to co-firing biomass and coal", Can. J. Chem. Eng., vol. 86, pp. 367-386, June 2008.

[21] L. Ma, J. M. Jones, M. Pourkashanian, and A. Williams, "Modelling the combustion of pulverized biomass in an industrial combustion test furnace", Fuel, vol. 86, pp. 1959-1965, August 2007.

[22] L. S. Pedersen, "Engineering models for low-NOx burners", Ph.D. thesis, Technical University of Denmark, Lyngby, Denmark, 1998.

[23] P.F. B. Hansen, K. H. Andersen, K. Wieck-Hansen, P. Overgaard, I. Rasmussen, F. J. Frandsen, L. A. Hansen, and K. Dam-Johansen, "Co-firing straw and coal in a 150-MWe utility boiler: in situ measurements", Fuel Process. Technol., vol. 54, pp. 207-225, March 1998.

[24] B. Damstedt, J. M. Pederson, D. Hansen, T. Knighton, J. Jones, C. Christensen, L. Baxter, D. Tree, "Biomass co-firing impacts on flame structure and emissions", Proc. Combust. Inst., vol. 31, pp. 2813-2820, January 2007.

[25] A. A. Tortosa-Masiá, F. Ahnert, H. Spliethoff, J. C. Loux, and K. R. G. Hein, "Slagging and fouling in biomass co-combustion", Thermal Science, vol. 9, no. 3, pp. 85-98, 2005.

[26] B. Arias, C. Pevida, F. Rubiera, and J. J. Pis, "Effect of biomass blending on coal ignition and burnout during oxy-fuel combustion", Fuel, vol. 87, pp. 2753-2759, September 2008.

[27] A. Demirbas, "Combustion characteristics of different biomass fuels," Prog. Energy Combust. Sci., vol. 30, Issue 2, pp. 219-230, 2004.

[28] A. Demirbas, "Potential applications of renewable energy sources, biomass combustion problems in boiler power systems and combustion related environmental issues", Prog. Energy Combust. Sci., vol. 31, Issue 2, pp. 171-192, 2005.

[29] B. M. Jenkins, L. L. Baxter, T. R. Miles Jr., and T. R. Miles, "Combustion properties of biomass", Fuel Process. Technol., vol. 54, pp. 17-46, March 1998.

[30] J. Werther, M. Saenger, E.-U. Hartge, T. Ogada, and Z. Siagi, "Combustion of agricultural residues", Prog. Energy Combust. Sci., vol. 26, pp. 1-27, February 2000.

[31] A. Bharadwaj, L. L. Baxter, and A. L. Robinson, "Effects of intraparticle heat and mass transfer on biomass devolatilization: experimental results and model predictions", Energy Fuels, vol. 18, pp.1021-1031, June 2004.

[32] R. I. Backreedy, L. M. Fletcher, J. M. Jones, L. Ma, M. Pourkashanian, and A. Williams, "Co-firing pulverised coal and biomass: a modeling approach”, Proc. Combust. Inst., vol. 30, pp. 2955-2964, January 2005.

[33] Y. Wang and L. Yan, "CFD studies on biomass thermochemical conversion", Int. J. Mol. Sci., vol. 9, pp. 1108-1130, 2008. [Open Access]. Available: www.mdpi.org/ijms

[34] T. Nussbaumer, "Combustion and co-combustion of biomass: fundamentals, technologies, and primary measures for emission reduction", Energy Fuels, vol. 17, pp. 1510-1521, September 2003.

[35] M. Losurdo, R. Korbee, B. Venneker, J. Kiel, and H. Spliethoff, "Ash and fouling deposition in pulverized co-firing biomass burners: CFD ash deposition modeling", in ECCOMAS Thematic Conference on Computational Combustion, Lisbon, Portugal, June 2124, 2005, pp. 1-17.

[36] L. Ma, M. Gharebaghi, R. Porter, M. Pourkashanian, J. M. Jones, and A. Williams, "Modelling methods for co-fired pulverised fuel furnaces", Fuel, vol. 88, pp. 2448-2454, December 2009.

[37] K. Davis, H.-Sh. Shim, D. Lignell, M. Denison, and L. Felix, "Evaluation of wood co-firing injection strategies using CFD simulations: pilot- and full-scale results", pp. 1-10, 2002. [Online]. Available: www.reaction-eng.com/downloads/clearwater_davis_ 2002.pdf [Accessed Oct. 15, 2009].

[38] J. Pallarés, A.Gil, C. Cortés, and C. Herce, "Numerical study of co-firing coal and Cynara cardunculus in a 350 MWe utility boiler", Fuel Process. Technol., vol. 90, pp. 1207-1213, October 2009.

[39] S. K. Kaer, L. Rosendahl, and P. Overgaard, "Numerical analysis of co-firing coal and straw", in the $4^{\text {th }}$ European CFD Conference, Athens, Greece, September 7-11, 1998, pp. 1194-1199. 
[40] T. Abbas, P. Costen, N. H. Kandamby, F. C. Lockwood, and J. J, Ou., "The influence of burner injection mode on pulverized coal and biosolid co-fired flames", Combust. Flame, vol. 99, pp. 617265, December 1994.

[41] B. Higgins, L. Yan, H. Gadalla, J. Meier, T. Fareid, G. Liu, M. Milewicz, A. Repczynski, M. Ryding, and W. Blasiak, "Biomass co-firing retrofit with ROFA for NOx reduction at EdF-Wroctaw Kogeneracja", in Energy Efficiency and Air Pollutant Control Conference, Wroclaw, Poland, September 21-25, 2009, pp. 1-27.

[42] A. M. Eaton, L. D. Smoot, S. C. Hill, and C. N. Eatough, "Components, formulations, solutions, evaluation, and application of comprehensive combustion models", Prog. Energy Combust. Sci., vol. 25, pp. 387-436, August 1999.

[43] A. Williams, M. Pourkashanian, and J. M. Jones, "Combustion of pulverised coal and biomass", Prog. Energy Combust. Sci., vol. 27, Issue 6, pp. 587-610, 2001.

[44] T. H. Fletcher, A. R. Kerstein, R. J. Pugmire, M. S. Solum, and D. M. Grant, "Chemical percolation model for devolatilization. 3. direct use of ${ }^{13} \mathrm{C}$ NMR data to predict effects of coal type", Energy Fuels, vol. 6: pp. 414-431, July 1992.

[45] J. C. Wurzenberger, S. Wallner, H. Raupenstrauch, and J. G. Khinast, "Thermal conversion of biomass: comprehensive reactor and particle modeling", AIChE J., vol. 48, pp. 2398-2411, October 2002.

[46] H. Spliethoff and K. R. G. Hein, "Effect of co-combustion of biomass on emissions in pulverized fuel furnaces", Fuel Proc. Technol., vol. 54, pp. 189-205, March 1998.

[47] C. Yin, L. Rosendahl, S. K. Kaer, T. J. Condra, "Use of numerical modeling in design for co-firing biomass in wall-fired burners", Chem. Eng. Sci., vol. 59, pp. 3281-3292, August 2004.

[48] D. Gera, M. P. Mathur, M. C. Freeman, and A. Robinson, "Effect of large aspect ratio of biomass particles on carbon burnout in a utility boiler", Energy Fuels, vol. 16, pp. 1523-1532, September 2002.

[49] G. H. Ganser, "A rational approach to drag prediction of spherical and nonspherical particles", Powder Technol., vol. 77, pp. 143-152, vol. 77, November 1993.

[50] C. Yin, L. Rosendahl, S. K. Kaer, and H.. Sorensen, "Modeling the motion of cylindrical particles in a nonuniform flow", Chem. Eng. Sci., vol. 58, pp. 3489-3498, August 2003.

[51] C. Di Blasi, "Modeling chemical and physical processes of wood and biomass pyrolysis" Prog. Energy Combust. Sci., vol. 34, pp. 47-90, February 2008.

[52] I. W. Smith, "The combustion rates of coal chars: a review", Proc. Combust. Inst., vol. 19, Issue 1, pp. 1045-1065, 1982.

[53] S. Jiménez, P. Remacha, J. C. Ballesteros, A. Giménez, and J. Ballester, "Kinetics of devolatilization and oxidation of a pulverized biomass in an entrained flow reactor under realistic combustion conditions", Combust. Flame, vol. 152, pp. 588-603, March 2008.

[54] J. Ballester and S. Jiménez, "Kinetic parameters for the oxidation of pulverised coal as measured from drop tube tests", Combust. Flame, vol. 142, pp. 210-222, August 2005.

[55] J. M. Jones, M. Pourkashanian, A. Williams, and D. Hainsworth, "A comprehensive biomass combustion model", Renewable Energy, vol. 19, pp. 229-234, January 2000.

[56] Y. Chen, S. Charpenay, A. Jensen, M. A. Wojtowicz, and M. A. Serio, "Modeling of biomass pyrolysis kinetics", Proc. Combust. Inst., vol. 27, Issue 1, pp. 1327-1334, 1998.

[57] H. Kobayashi, J. B Howard, and A. F. Sarofim, "Coal devolatilization at high temperatures", Proc. Combust. Inst., vol. 16, Issue 1, pp. 411-425, 1977.
[58] C. Di Blasi, "Heat, momentum and mass transport through a shrinking biomass particle exposed to thermal radiation", Chem. Eng. Sci., vol. 51, pp. 1121-1132, April 1996.

[59] M. Muller-Hagedorn, H. Bockhorn, L. Krebs, and U. Muller, "Investigation of thermal degradation of three wood species as initial step in combustion of biomass", Proc. Combust. Inst., vol. 29, Issue 1, pp. 399-406, 2002.

[60] S. Niksa, "Predicting the rapid devolatilization of diverse forms of biomass with bio-FLASHCHAIN", Proc. Combust. Inst., vol. 28, Issue 2, pp. 2727-2733, 2000.

[61] A. A. Rostami, M. R. Hajaligol, and S. E. Wrenn, "A biomass pyrolysis sub-model for CFD applications", Fuel, vol. 83, pp. 1519-1525, August 2004.

[62] C. D. Sheng, and J. L. T. Azevedo, "Modeling biomass devolatilization using the chemical percolation devolatilization model for the main components", Proc. Combust. Inst., vol. 29, Issue 1, pp. 407414, 2002.

[63] T. Abbas, M. M. Awais, and F. C. Lockwood, "An artificial intelligence treatment of devolatilization for pulverized coal and biomass in co-fired flames", Combust. Flame, vol. 132, pp. 305-318, February 2003.

[64] R. H. Hurt and R. E. Mitchell, "Unified high-temperature char combustion kinetics for a suite of coals of various rank", in $24^{\text {th }}$ Symposium (International) on Combustion, The Combustion Institute, 1992, pp. 1243-1250.

[65] R.I. Backreedy, J.M. Jones, M. Pourkashanian, and A. Williams, "Modeling the reaction of oxygen with coal and biomass chars", Proc. Combust. Inst., vol. 29, Issue 1, pp. 415-422, 2002.

[66] N. Syred, K. Kurniawan, T. Griffiths, T. Gralton, and R. Ray, "Development of fragmentation models for solid fuel combustion and gasification as subroutines for inclusion in CFD codes", Fuel, vol. 86, pp. 2221-2231, September 2007.

[67] V. Doshi, H. B. Vuthaluru, R. Korbee, and J. H. A. Kiel, "Development of a modeling approach to predict ash formation during cofiring of coal and biomass", Fuel Process. Technol., vol. 90, pp. 1148-1156, September 2009.

[68] G. C. De Soete, "Overall reaction rates of $\mathrm{NO}$ and $\mathrm{N}_{2}$ formation from fuel nitrogen", Proc. Combust. Inst., vol. 15, Issue 1, pp. 1093-1102, 1975.

[69] M. Sami, K. Annamalai, S. Dhanapalan, and M. Wooldridge, "Numerical simulation of blend combustion of coal and feedlot waste in a swirl burner", ASME-HDT, vol. 364, Issue 2, pp. 363372, November 1999.

[70] S. Dhanapalan, K. Annamalai, and P. Daripa, "Turbulent combustion modeling of coal:biomass blends in a swirl burner I - preliminary results", ASME, pp. 1-6, 1997. [Online]. Available: www. math.tamu.edu/ pkd/pubs/reprints/asme-97.pdf [Accessed Oct. 21, 2009].

[71] S. Dhanapalan, K. Annamalai, and P. Daripa, "Turbulent combustion modeling coal: biosolid blends in a swirl burner", in $8^{\text {th }}$ Annual Energy Week, vol. IV, ETCE, ASME, January 1997. pp. 415-423.

[72] A. K. Sadhukhan, P. Gupta, T. Goyal, and R. K. Saha, "Modelling of pyrolysis of coal-biomass blends using thermogravimetric analysis", Bioresour. Technol., vol. 99, pp. 8022-8026, November 2008.

[73] E. Kastanaki and D. Vamvuka, "A comparative reactivity and kinetic study on the combustion of coal-biomass char blends", Fuel, vol. 85, pp. 1186-1193, June 2006. 